Research Article

\title{
Solar power plants site selection for sustainable ecological development in Nigde, Turkey
}

\author{
Orhun Soydan $^{1}$ (D)
}

Received: 30 March 2020 / Accepted: 29 December 2020 / Published online: 8 January 2021

(C) The Author(s) 2021 OPEN

\begin{abstract}
Turkey's population is constantly increasing, and thus, the energy consumption is also increasing. Wind turbines, nuclear power plants, and boron and uranium resources are used for energy needs. Turkey meets its energy needs using these resources. Sun which is a natural and unlimited resource among these resources is one of the most important natural energy resources. The most important issue to consider in order to utilize solar energy in the most efficient way and to obtain advantages is the selection of the suitable place for solar plants. The aim of this study is to select the most suitable location for solar energy plants and provide to build solar power plants in suitable places. Eleven data layers (sunshine duration, solar radiation, slope, aspect, road, water sources, residential areas, earthquake fault line, mine areas, power line and transformers) that were prepared using analytical hierarchy process (AHP) method in GIS were used and analysed. Based on the results of the analysis, the location of the areas where solar energy could be built was selected. As a result of the study, it was determined that in particular the north-east of the Nigde is the most suitable for solar plants. Ulukisla district has the most suitable feature for solar plants among the Nigde districts. $80 \%$ of the existing solar plants are located in the detected areas. It has been determined that the other $20 \%$ of the solar plant is also in the suitable areas, but their location is not suitable for the most efficiency.
\end{abstract}

Keywords Solar energy · Site selection · GIS · Analytical hierarchy process · Sustainable ecological development

\section{Introduction}

Fossil fuels such as coal, natural gas and petroleum are among the most preferred energy sources nowadays. These resources are considered to be unlimited in the world and are used unplanned. These energy sources are not unlimited, and they are negatively affected by some reasons such as unconscious use, greenhouse gases and industrialization [1]. One of the preferred solutions to use these resources more efficiently and to minimize the greenhouse gas effect is renewable energy sources $[2,3]$.

Renewable energy sources have been attracted great attention in recent years. Although global energy that related to $\mathrm{CO}_{2}$ emissions have increased, some countries have decreased their electricity generation emission values due to the use of renewable energy capacity. According to the data of renewable energy policies, when the renewable energy investments around the world are examined, the total investment for 2017 was 279.8 billion dollars [4].

The advantages the use of renewable energy are recognized worldwide as a result of significant investments made in developed countries such as China, USA, Japan, India and Germany [5].

In 2018, many important steps were taken to renewable electricity generation in some parts of the world. For example, Australia increased its renewable energy sources to $20 \%$ for the first time, while Costa Rica provided 300 days

Orhun Soydan, orhunsoydan@ohu.edu.tr| 'Landscape Architecture Department, Faculty of Architecture, Niğde Ömer Halisdemir University, Niğde, Turkey.

SN Applied Sciences (2021) 3:41 | https://doi.org/10.1007/s42452-020-04112-z 
of energy to the countries from renewable energy with $100 \%$ [5].

In early 2019 , renewable electricity generation in the USA approached levels of coal-fired power generation, and renewable generation nearly doubled between 2008 and 2018 years. In Europe, Portugal generated more than half of its electricity consumption from renewable sources in 2018 , while the UK was set annual records in production shares for both onshore $(9.1 \%)$ and offshore $(8 \%)$ for the wind energy. For the first time, the EU has generated more than $15 \%$ of annual electricity using wind and solar power [5].

In this respect, the next century seems to be important in using the sun and its derivatives and other inexhaustible and clean energy resources $[6,7]$.

There are a large number of alternative energy sources that can replace fossil fuels in energy use such as wind energy and hydropower. In addition to these resources, solar energy is a natural resource that can replace fossil fuels because they cause less harm to the environment and provide the unlimited energy $[8,9]$. In addition to environmental contributions, solar energy can provide more economic gain compared to fossil resources.

Since these resources are more sustainable than other sources, they can meet the world's energy consumption demands. Today, we can say that energy consumption based on solar energy was increased by $50 \%$. Studies estimate that the global share of the solar energy consumption will be $16 \%$ by 2050 [10]. As of 2020 , the global share of energy consumption based on solar energy is $12 \%$ in the world [11].

Although solar energy sources have ecological and economic advantages, there are some difficulties that prevent wide use worldwide. Firstly, as a result of the geographical location, the desired efficiency cannot be obtained from the solar energy. This potential decreases or increases depending on the geographical position of the study area. The other point is that they need very large areas for the built of solar energy panels. For example, as a result of the study, a total of 80 acres is needed for a solar panel area of $5 \mathrm{MW}$ power. An average of 20 acres of area is needed for a $1 \mathrm{MW}$ solar panel [12].

Later, since the materials that are used in the built of the panels are metal or similar, these materials cause negativity in terms of aesthetic appearance in a large area. Another negative feature is that not all of these systems are used as energy. Energy losses occur in the conversion of the energy that is obtained from the panels into electrical energy.

As a result of researches, it has been determined that the efficiency of solar panels is between 15 and $20 \%$ [13]. As a result of the technical studies carried out in the recent years, this efficiency has increased up to $40 \%[14$,
15]. Another negative feature is that the investment costs of solar panels are very high [16]. Soydan [12] stated that the costs for the solar panels are recovered after 9 years. However, considering that the average usage time of the panels is 20 years, it can be said that this period is not too long [17].

\subsection{Solar energy in Turkey}

Turkey's economic growth, increasing population, industrialization and energy needs in parallel with the improvement of living conditions is increasing rapidly. Turkey is considered poor in terms of fossil fuels.

The domestic production of the energy demand decreased by $22 \%$ between the 1990 to 2013 years, and foreign dependence has increased at the same rate. $43-50 \%$ is the share of natural gas in electricity production over the last decade in Turkey. This is a clear proof that high dependence on imported natural gas [18].

The use of the solar energy is very important to ensure diversity of sources of electricity production, struggling to reduce global warming and dependence on foreign sources for the fossil fuels.

According to the 2018 data of the Ministry of Energy [19], $31.9 \%$ of the power is hydraulic, $25.6 \%$ is natural gas, $21.5 \%$ is coal, $7.9 \%$ is wind, $5.7 \%$ is solar, $1.4 \%$ is by geothermal and $5.9 \%$ is from other sources. In 2018, the number of solar power plants in operation is 5868. Total solar energy power is reached $5063.0 \mathrm{MW}$, of which 4,981.2 MW is unlicensed, and $81.8 \mathrm{MW}$ is licensed.

The share of solar panels in total electricity production in Turkey has increased to $2.5 \%$ with $7477.3 \mathrm{GWh}[19,20]$. Energy and Natural Resources Ministry [19-21] published the "World and Turkey's Energy and Natural Resources View"; according to the report, as of 2014, within the total electricity production of $251.963 \mathrm{GWh}, 17.4 \mathrm{GWh}$ generation $(0.01 \%$ share) was from solar energy; as of 2016 , it has reached $972 \mathrm{GWh}$ in total production of $273.387 \mathrm{GWh}$ (0.36\% share) [19-21].

In 2018, the total power of unlicensed solar power plants increased to $4.981 \mathrm{MW}$. The annual average increase in electricity demand for the 20-year period in 2019 was calculated as $2.90 \%-3.84 \%$ according to different scenarios. It is predicted that it will reach 376 billion kWh in 2023 and 613 billion $\mathrm{kWh}$ in 2039. It is predicted that the share of renewable energy sources will increase even more in meeting this demand [19-21].

\subsection{Approach to the build of solar panels}

It is possible to gather the studies on solar panels under three groups. Some of them are the studies (Klepacha et al. 
[22], Bayrakçı and Tezer (2019) [23], Baka et al. [24]) on the cost analysis of solar panels.

In the second group, there are studies (Strielkowski et al. [25], Da Cunha et al. [26], Kocaman et al. [27]) to determine the advantages of solar panels in terms of energy. In the last group, there are studies (Koç et al. [28], Wang et al. [29]) on the site selection for the most energy efficiency from solar panels. Since this study focuses on select the suitable location in terms of solar panels, it can be included in this group.

Although there are many studies (Wang et al. [29], Alsabbagh [30], Suri [31]) related to solar panels in the world, Turkey also does not have too many studies (Geçen [32], Sarsıcı [33], Oral et al. [34]) on this subject.

The studies are mostly focus on cost analysis. However, the most important factor affecting the cost analysis is the site selection. There are very few studies for site selection of solar panels in Turkey. The criteria that were used in the studies were found to be insufficient. This study aims to determine the most suitable location for solar panels using AHP method and various criteria.

It is thought that this study will contribute significantly to the literature in Turkey in terms of the selected method and criteria. The number of these studies is quite low, especially in terms of landscape architecture professional discipline. It can be thought that the study will contribute to this issue as well.

Nigde has one of the most sun in Turkey. Turkey's annual solar energy potential is 380 billion KWh. Average annual sunshine duration per square metre is $2640 \mathrm{~h}$, and average annual solar energy potential is $1,303 \mathrm{kWh}$.

These data correspond to a power of $3.6 \mathrm{kWh}$ with a sunshine duration of approximately $7.2 \mathrm{~h}$ per square metre per day [19]. Compared to the other provinces in the region, Nigde is the leader with the highest annual average global radiation value of $1620 \mathrm{kWh} / \mathrm{m}^{2}$-year.

The average daily sunshine duration of Nigde is $8.03 \mathrm{~h}$, and the average daily global radiation value is $4.44 \mathrm{kWh} /$ $\mathrm{m}^{2}$-day [35]. Nigde is suitable area for the solar panel investments due to reasons such as weak pasture areas and high solar radiation values.

Nigde gets sun about 300 days of the year. Nigde has a very wavy topography due to its location. Due to this topography and the sunshine duration, Nigde is in a very suitable region in terms of solar panels built. That is why Nigde was selected as the study area.

The aim of this study is to select the most suitable location for solar energy plants and provide to build solar power plants in suitable places. Eleven data layers (sunshine duration, solar radiation, slope, aspect, road, water sources, residential areas, earthquake fault line, mine areas, power line and transformers) that were prepared using AHP analysis method in GIS were used and analysed.
Based on the results of the analysis, the location of the areas where solar energy could be built was selected.

\section{Material and methods}

\subsection{Material}

The study area includes the city of Nigde as a whole. Nigde is located in $34^{\circ} 30^{\prime} 10^{\prime \prime}-34^{\circ} 45^{\prime} 00^{\prime \prime}$ eastern longitude and $37^{\circ} 54^{\prime} 00^{\prime \prime}-38^{\circ} 06^{\prime} 30^{\prime \prime}$ northern latitude. The size of the study area is $7795.22 \mathrm{~km}^{2}$. Nigde has a climate which is hot and dry in summers, and cold and snowy in winters.

According to the 84-year climate values covering the 1935-2019 years, the lowest temperature was found in January with $-25.6{ }^{\circ} \mathrm{C}$ and the highest temperature in August with $38.5 \mathrm{oC}$. The annual rainfall varied between 5.2 and $48.7 \mathrm{~mm}$ [36].

In this study, aspect and slope maps were produced using elevation map which has $30 \mathrm{~m}$ resolution. The properties of the data which were used in the study are given in Table 1.

LULC (land-use and land-cover) classes were defined from satellite images obtained in 2019 using visual interpretation through ENVI 5.3, Harris Geospatial Solutions, USA. Then, the LUCC maps were classified into nine different land-use classes using the supervised classification method [37, 38]:

(1) urban areas,

(2) sparsely vegetated areas,

(3) industrial units,

(4) pasture lands,

(5) agricultural lands,

(6) broadleaved forest,

(7) coniferous forest,

(8) watercourses,

Table 1 Properties of the data

\begin{tabular}{lll}
\hline Data & Source & Resolution \\
\hline Elevation maps & $\begin{array}{c}\text { https://www.eorc.jaxa.jp/ALOS/en/ } \\
\text { aw3d30/data/index.htm }\end{array}$ & $30 \mathrm{~m}$ \\
Power lines & https://www.openstreetmap.org/ & $0.3 \mathrm{~m}$ \\
Transformers & & \\
Water sources & \\
Roads & \\
$\begin{array}{l}\text { Fault lines } \\
\text { Residential areas }\end{array}$ & \\
Mining areas & \\
Climate data & $\begin{array}{c}\text { General Directorate of Meteorol- } \\
\text { ogy (https://mgm.gov.tr/) }\end{array}$ & - \\
&
\end{tabular}




\section{(9) bare land.}

The reason for using these data in the study is to remove the agricultural areas, residential areas and water surfaces in the area. The suitability or unsuitability of these areas will not change the result. It is very difficult to build solar panels on these areas. Residential areas and water surfaces are insufficient and impossible in terms of areas where solar panels need to be build. Therefore, these areas were removed in the final map. Agricultural areas were removed on the final map due to its ecological damage.

\subsection{Method}

The data that were determined for the study were arranged in the GIS and shown with the created maps. The data were scored by the "Euclidean distance" method. The normalized data were reclassified and divided into 5 classes; it was scored by giving the most suitable value " 5 " and the least suitable value " 1 ". Suitable areas for solar plant were determined and visualized by adding on the satellite image.

In the solar energy site selection, the AHP method in GIS was used to determine the most suitable power plant areas to be built for the province of Nigde. After determining the necessary criteria, some arrangements have been made to process the data. In the first stage, all data were converted to UTM, WGS84 and $36 \mathrm{~N}$ coordinate system. After the data were converted to the suitable coordinate system, the data in vector format were converted to a raster format. All data which were used in the study were converted into raster format. The purpose of this transformation is to ensure that each factor is scored in the specified class range (with the Reclassify command), and all data are overlaid with the weight coefficients (with the Weighted overlay command) in order to determine the suitable areas for solar panels.

Raster data were analysed based on the "Euclidean distance" method. After this process, the score (suitability) of the layer that expresses each criterion was determined according to the quality. Criteria maps were created by standardizing the layers. The values in the maps are provided in a fixed range between 1 and 5 . It has been determined that many criteria are used in the build of the solar power plant. ArcGIS software was used in the study. In the study, 11 factors were determined in order to determine suitable areas for solar panels. The determined factors are that:

1. Sunshine duration

2. Solar radiation

3. Slope

4. Aspect

\section{SN Applied Sciences}

5. Proximity to the power line

6. Proximity to transformers

7. Distance to water resource areas

8. Distance to fault line

9. Proximity to residential areas

10. Distance to mining areas

11. Proximity to roads

Nigde is not located in an area that has not a lot of rainfall or natural disasters. Temperature value is not important for panels, and sunshine duration and solar radiation values are important. Therefore, climatic parameters were ignored within the scope of the study. However, it should not be forgotten that these factors are valid only for this study and the number of criteria may increase or decrease depending on the region. There are many factors in determining the site selection of the solar power plant. In addition, while calculating the scores for each classification, it was benefited from previous studies on this subject such as Jung et et al. [9] and Kum et al. [7]. Maps of sunshine duration, solar radiation, slope, aspect, proximity to the power line, proximity to transformers, distance to water resource areas, distance to fault line, proximity to residential areas, distance to mining areas, proximity to roads were done according to the values given in Table 2 .

It is advantageous to use the GIS method in order to ensure that these factors are compatible, monitored, interpreted and managed. "Analytical hierarchy process" (AHP) method was used to determine the weight coefficients of the factors.

AHP is a mathematical method that takes into account the priorities of the group or individual and evaluates the qualitative and quantitative variables together [39, 40]. As it is a simple, easy to use and understandable method, it is a frequently used technique among multicriteria decision-making methods.

In this study, it was tried to reach the results by using too many factors. AHP method was used to determine the weight coefficients of the factors among each other and to determine the weight coefficients of each factor in the site selection of the solar energy panels.

AHP method calculates the consistency rate as a result of determining the weight coefficients established among the factors. This consistency rate gives an idea about whether this relationship is right or wrong. This is a very important step to prove the accuracy of the study. If the relationship between the number of factors and these factors is determined clearly, the accuracy of the results will increase. Due to these features, AHP method was preferred in the study. 
Table 2 Weighting coefficients of the evaluation criteria

\begin{tabular}{|c|c|c|}
\hline Factors & Classification & Value \\
\hline \multirow[t]{5}{*}{ Slope (\%) } & $\% 1$ & 5 \\
\hline & $\% 2$ & 4 \\
\hline & $\% 3$ & 3 \\
\hline & $\% 4$ & 2 \\
\hline & $\% 5$ & 1 \\
\hline \multirow[t]{5}{*}{ Road classification } & $21,000 \mathrm{~m}<$ & 1 \\
\hline & $13,500 m-21,000 m$ & 2 \\
\hline & $4500 m-13,500 m$ & 3 \\
\hline & $2000 m-4500 m$ & 4 \\
\hline & $100 m-2000 m$ & 5 \\
\hline \multirow[t]{5}{*}{ Aspect } & S, SE, SW and FLAT & 5 \\
\hline & $\mathrm{E}$ & 4 \\
\hline & $\mathrm{NE}$ & 3 \\
\hline & NW and W & 2 \\
\hline & $\mathrm{N}$ & 1 \\
\hline \multirow[t]{5}{*}{ Power line classification } & $18,000 \mathrm{~m}<$ & 1 \\
\hline & $12,000 m-18,000 m$ & 2 \\
\hline & $6000 m-12,000 m$ & 3 \\
\hline & $1800 m-6000 m$ & 4 \\
\hline & $0000 m-1800 m$ & 5 \\
\hline \multirow[t]{5}{*}{ Transformer analysis } & $40,000 \mathrm{~m}<$ & 1 \\
\hline & $30,000 m-40,000 m$ & 2 \\
\hline & $24,000 m-30,000 m$ & 3 \\
\hline & $15,000 m-24,000 m$ & 4 \\
\hline & $0 \mathrm{~m}-15,000 \mathrm{~m}$ & 5 \\
\hline \multirow[t]{5}{*}{ Sunshine duration hours/year } & $<1500$ & 1 \\
\hline & $1500-2000$ & 2 \\
\hline & $2000-2200$ & 3 \\
\hline & $2200-2500$ & 4 \\
\hline & $>2500$ & 5 \\
\hline \multirow[t]{5}{*}{ Distance to water resource areas } & $0000 m-1200 m$ & 1 \\
\hline & $1200 m-2800 m$ & 2 \\
\hline & $2800 m-4700 m$ & 3 \\
\hline & $4700 m-7100 m$ & 4 \\
\hline & $7100 \mathrm{~m}<$ & 5 \\
\hline \multirow[t]{5}{*}{ Distance to fault lines } & $0000 m-4500 m$ & 1 \\
\hline & $4500 m-9000 m$ & 2 \\
\hline & $9000 m-15,000 m$ & 3 \\
\hline & $15,000 m-21,000 m$ & 4 \\
\hline & $21,000 \mathrm{~m}<$ & 5 \\
\hline \multirow[t]{5}{*}{ Proximity to residential areas } & $500 m-3000 m$ & 1 \\
\hline & $3000 m-7500 m$ & 2 \\
\hline & $7500 m-12,000 m$ & 3 \\
\hline & $12,000 m-18,000 m$ & 4 \\
\hline & $18,000 \mathrm{~m}<$ & 5 \\
\hline \multirow[t]{5}{*}{ Distance to mining areas } & $0000 m-4500 m$ & 1 \\
\hline & $4500 m-7500 m$ & 2 \\
\hline & $7500 m-14,000 m$ & 3 \\
\hline & $14,000 m-20,000 m$ & 4 \\
\hline & $20,000 \mathrm{~m}<$ & 5 \\
\hline
\end{tabular}

Table 2 (continued)

\begin{tabular}{lll}
\hline Factors & Classification & Value \\
\hline Solar radiation $\mathrm{kWh} / \mathrm{m}^{2}$ & $<1500$ & 1 \\
& $1500-1550$ & 2 \\
& $1550-1600$ & 3 \\
& $1600-1650$ & 4 \\
& $1650<$ & 5 \\
\hline
\end{tabular}

\subsubsection{Analytical hierarchy process (AHP)}

AHP is a mathematical method that takes into account the priorities of the group or individual and evaluates the qualitative and quantitative variables together. There are many studies (Garni et al. [41], Çolak and Kaya [42]) in which AHP method is used for the build of solar panels. As it is a simple, easy to use and understandable method, it is a frequently used technique among multi-criteria decision-making methods. AHP consists of four steps.

Step 1 Decision-making problem is identified.

The decision-maker determines the necessary factors and sub-factors. At this stage, a survey study can be conducted or the opinions of experts on the subject can be obtained.

Step 2 The binary comparisons matrix is created.

This step is the most important of AHP. After determining the factors and sub-factors, the degree of importance of these factors among themselves is determined.

For this, binary comparison matrix is created. This matrix is " $\mathrm{A}$ " (Table 3). The 1-9 scale of importance which is recommended by Saaty [43] is used to create these matrices (Table 4).

"W" values in the matrix show how important the " $\mathrm{i}$ "factor is compared to the " $\mathrm{j}$ " factor.

Values on the diagonal of the created matrix are expressed by a number. "I" and "j" are the same criteria. Factors which are considered for comparison should be homogeneous. In terms of consistency and accuracy of the scale, the number of alternatives should be less than nine. If it is

Table 3 1-9 importance scale $[43,44]$

\begin{tabular}{ll}
\hline Value & Explanation \\
\hline 1 & Equally important \\
3 & Moderately important \\
5 & Strongly important \\
7 & Very strongly important \\
9 & Certainly important \\
$2,4,6,8$ & Intermediate values \\
\hline
\end{tabular}


Table 4 Matrix A obtained by binary comparisons [44]

\begin{tabular}{lllll}
\hline & Cri.1 & Cri.2 & $\cdots$ & Criteria(n) \\
\hline Criteria1 & $\mathrm{W}_{1} / \mathrm{W}_{1}$ & $\mathrm{~W}_{1} / \mathrm{W}_{2}$ & $\ldots$ & $\mathrm{W}_{1} / \mathrm{W}_{\mathrm{n}}$ \\
Criteria2 & $\mathrm{W}_{2} / \mathrm{W}_{1}$ & $\mathrm{~W}_{2} / \mathrm{W}_{2}$ & $\ldots$ & $\mathrm{W}_{2} / \mathrm{W}_{\mathrm{n}}$ \\
$\ldots$ & $\ldots$ & $\ldots$ & $\ldots$ & $\ldots$ \\
Criteria(n) & $\mathrm{W}_{\mathrm{n}} / \mathrm{W}_{1}$ & $\mathrm{~W}_{\mathrm{n}} / \mathrm{W}_{2}$ & $\ldots$ & $\mathrm{W}_{\mathrm{n}} / \mathrm{W}_{\mathrm{n}}$ \\
\hline
\end{tabular}

taken more than nine, clustering should be done homogeneously according to common features [44].

Step 3 The weight factor is calculated.

The comparison matrix shows the importance levels of factors relative to each other. But to determine the weight of these factors within all factors, column vectors that make up the comparison matrix are used. Finally, column " $B$ " with $\mathrm{n}$ number and $\mathrm{n}$ components is created (Eq. 1).

$b_{i j}=\frac{a_{i j}}{\sum_{i \_1}^{n} a_{i j}}$

" $\mathrm{a}_{\mathrm{ij}}$ " is the row and column elements of the binary comparison matrix.

With the number of factors here, the more $B$ column vectors are obtained. When $n$ number $B$ column vectors are combined in a matrix format, the $\mathrm{C}$ matrix is formed.

The arithmetic mean of the row values of the matrix $C$ is obtained, and the $\mathrm{W}$ column vector weight matrix is obtained (Eq. 2).

$W_{i}=\frac{\sum_{j=1}^{n} c_{i j}}{n}$

Step 4 Consistency in factor comparisons is measured.

AHP is consistent in itself. However, the accuracy of the results depends on the consistency in the decision-maker's comparison between the factors. In order to measure the consistency in these comparisons, CR value which is called accuracy rate is calculated, and the consistency of the weight matrix can be tested. Therefore, the consistency of the model is checked by comparisons between factors. The calculation of the $C R$ value is based on comparing the number of factors with a coefficient called the base value $(\lambda)$. When calculating the $\lambda$ value, the $D$ column vector is obtained from the comparison matrix $A$ and the weight matrix of $W$. The basis value $(E)$ for each evaluation factor is obtained from the section of the mutual elements of the weight column $D$ and the weight matrix of W. (Eq. 3). The arithmetic mean of these values gives the basic value ( $\lambda$ ) for comparison (Eq. 4).

$E_{i}=\frac{d_{i}}{w_{i}}(i=1,2, \ldots, n)$
Table 5 Random indicator

\begin{tabular}{llllll}
\hline $\mathrm{n}$ & $\mathrm{Rl}$ & $\mathrm{N}$ & $\mathrm{Rl}$ & $\mathrm{N}$ & $\mathrm{Rl}$ \\
\hline 1 & 0.00 & 6 & 1.24 & 11 & 1.51 \\
2 & 0.00 & 7 & 1.32 & 12 & 1.53 \\
3 & 0.58 & 8 & 1.41 & 13 & 1.56 \\
4 & 0.90 & 9 & 1.45 & 14 & 1.57 \\
5 & 1.12 & 10 & 1.49 & 15 & 1.59 \\
\hline
\end{tabular}

$\lambda=\frac{\sum_{i=1}^{n} E_{i}}{n}$

After calculating the basic value $\lambda$, the consistency indicator $(\mathrm{Cl})$ is calculated with Eq. (5).

$\mathrm{Cl}=\frac{\lambda-\mathrm{n}}{\mathrm{n}-1}$

The value of " $n$ " in the equations is the number of factors. Finally, the $\mathrm{Cl}$ value is divided by the standard correction value which is called the random indicator (RI), shown in Table 4, and the CR value that is called consistency ratio is obtained (Eq. 6).

The value corresponding to the number of factors is selected from Table 5 .

For example, the RI value to be used in a 3-factor comparison will be 0.58 according to Table 5 .

$\mathrm{CR}=\frac{\mathrm{Cl}}{\mathrm{Rl}}$

For the comparisons made by the decision-maker to be consistent, the calculated CR value must be less than 0.10 .

If the $C R$ value is higher than 0.10 , there is either a calculation error in AHP or it is inconsistent in the decisionmaker comparison.

\subsubsection{Using AHP method in the study}

" $\mathrm{A}$ " matrix where binary comparisons were made according to the importance of the factors selecting site in the study area was created (Table 6). Weight factor was calculated for each criterion. For this, the elements in each column of the binary comparison matrix were divided by the sum of the column it is found (Eq. 1) and the "B" column vectors were calculated.

Since there were 11 factors, 11 " $\mathrm{B}$ " column matrices were created.

By combining the " $\mathrm{B}$ " column matrices, the " $\mathrm{C}$ " matrix was obtained (Table 7).

By taking the average of each line in the " $\mathrm{C}$ " matrix, the "W" weight matrix was created according to the Eq. (2) (Table 8). The model was developed for this study, and it is based on the statistical weights for each variable calculated in the previous item. 
Table 6 Binary comparisons of criteria which affect selected suitable areas
Table 7 "C" matrix from " $\mathrm{B}$ " matrices

\begin{tabular}{llllllllllll}
\hline Factors & C1 & C2 & C3 & C4 & C5 & C6 & C7 & C8 & C9 & C10 & C11 \\
\hline Sunshine duration (C1) & 1 & 1 & 3 & 3 & 5 & 5 & 5 & 5 & 5 & 5 & 5 \\
Solar radiation (C2) & 1 & 1 & 3 & 3 & 5 & 5 & 5 & 5 & 5 & 5 & 5 \\
Slope (C3) & $1 / 3$ & $1 / 3$ & 1 & $1 / 3$ & 2 & 2 & 2 & 2 & 2 & 2 & 2 \\
Aspect (C4) & $1 / 3$ & $1 / 3$ & 3 & 1 & 3 & 3 & 3 & 3 & 3 & 3 & 3 \\
Proximity to the power line (C5) & $1 / 5$ & $1 / 5$ & $1 / 2$ & $1 / 3$ & 1 & 1 & 3 & 3 & 3 & 3 & 3 \\
Proximity to transformers (C6) & $1 / 5$ & $1 / 5$ & $1 / 2$ & $1 / 3$ & 1 & 1 & 3 & 3 & 3 & 3 & 3 \\
Distance to water resou. areas (C7) & $1 / 5$ & $1 / 5$ & $1 / 2$ & $1 / 3$ & $1 / 3$ & $1 / 3$ & 1 & 1 & 1 & 1 & 1 \\
Proximity to roads (C8) & $1 / 5$ & $1 / 5$ & $1 / 2$ & $1 / 3$ & $1 / 3$ & $1 / 3$ & 1 & 1 & 1 & 1 & 1 \\
Distance to fault line (C9) & $1 / 5$ & $1 / 5$ & $1 / 2$ & $1 / 3$ & $1 / 3$ & $1 / 3$ & 1 & 1 & 1 & 1 & 1 \\
Proximity to residential areas (C10) & $1 / 5$ & $1 / 5$ & $1 / 2$ & $1 / 3$ & $1 / 3$ & $1 / 3$ & 1 & 1 & 1 & 1 & 1 \\
Distance to mining areas (C11) & $1 / 5$ & $1 / 5$ & $1 / 2$ & $1 / 3$ & $1 / 3$ & $1 / 3$ & 1 & 1 & 1 & 1 & 1 \\
Consistency Rate (CR): 0.05 & & & & & & & & & &
\end{tabular}

\begin{tabular}{llllllllllll}
\hline Factors & C1 & C2 & C3 & C4 & C5 & C6 & C7 & C8 & C9 & C10 & C11 \\
\hline (C1) & 0.25 & 0.25 & 0.22 & 0.31 & 0.27 & 0.27 & 0.19 & 0.19 & 0.19 & 0.19 & 0.19 \\
(C2) & 0.25 & 0.25 & 0.22 & 0.31 & 0.27 & 0.27 & 0.19 & 0.19 & 0.19 & 0.19 & 0.19 \\
(C3) & 0.08 & 0.08 & 0.07 & 0.03 & 0.11 & 0.11 & 0.08 & 0.08 & 0.08 & 0.08 & 0.08 \\
(C4) & 0.08 & 0.08 & 0.22 & 0.10 & 0.16 & 0.16 & 0.12 & 0.12 & 0.12 & 0.12 & 0.12 \\
(C5) & 0.05 & 0.05 & 0.04 & 0.03 & 0.05 & 0.05 & 0.12 & 0.12 & 0.12 & 0.12 & 0.12 \\
(C6) & 0.05 & 0.05 & 0.04 & 0.03 & 0.05 & 0.05 & 0.12 & 0.12 & 0.12 & 0.12 & 0.12 \\
(C7) & 0.05 & 0.05 & 0.04 & 0.03 & 0.02 & 0.02 & 0.04 & 0.04 & 0.04 & 0.04 & 0.04 \\
(C8) & 0.05 & 0.05 & 0.04 & 0.03 & 0.02 & 0.02 & 0.04 & 0.04 & 0.04 & 0.04 & 0.04 \\
(C9) & 0.05 & 0.05 & 0.04 & 0.03 & 0.02 & 0.02 & 0.04 & 0.04 & 0.04 & 0.04 & 0.04 \\
(C10) & 0.05 & 0.05 & 0.04 & 0.03 & 0.02 & 0.02 & 0.04 & 0.04 & 0.04 & 0.04 & 0.04 \\
(C11) & 0.05 & 0.05 & 0.04 & 0.03 & 0.02 & 0.02 & 0.04 & 0.04 & 0.04 & 0.04 & 0.04 \\
\hline
\end{tabular}

Table 8 "W" matrix from " $\mathrm{C}$ " matrices

\begin{tabular}{llllllllllll}
\hline Factors & C1 & C2 & C3 & C4 & C5 & C6 & C7 & C8 & C9 & C10 & C11 \\
\hline Value & 0.23 & 0.23 & 0.08 & 0.13 & 0.08 & 0.08 & 0.04 & 0.04 & 0.04 & 0.04 & 0.04 \\
\hline
\end{tabular}

$$
\begin{aligned}
\mathrm{IR} & =(0.23 * \text { Sunshine }+0.23 * \text { Solar radiation }+0.08 * \text { Slope } \\
& +0.13 * \text { Aspect }+0.08 * \text { Proximity to the power line } \\
& +0.08 * \text { Proximity to transformers } \\
& +0.04 * \text { Distance to water surfaces } \\
& +0.04 * \text { Proximity to roads }+0.04 \\
& * \text { Distance to fault line }+0.04 \\
& * \text { Proximity to residential areas }+0.04 \\
& * \text { Distance to mining areas }) .
\end{aligned}
$$

According to Table 8 , sunshine duration and solar radia-

\begin{tabular}{|c|c|c|c|}
\hline \multirow[t]{11}{*}{$\mathrm{D}$} & 2.90 & $E$ & 12.64 \\
\hline & 2.00 & & 8.72 \\
\hline & 0.99 & & 12.52 \\
\hline & 1.60 & & 12.69 \\
\hline & 0.93 & & 11.98 \\
\hline & 0.93 & & 11.98 \\
\hline & 0.43 & & 11.90 \\
\hline & 0.43 & & 11.90 \\
\hline & 0.43 & & 11.90 \\
\hline & 0.43 & & 11.90 \\
\hline & 0.43 & & 11.90 \\
\hline
\end{tabular}
tion were the highest value $23 \%$ (C1 and $\mathrm{C2}$ ). Then there was aspect (C4) with $13 \%$ and slope (C3) with $6 \%$. The consistency checks of the weight values and the model were made. For this, the matrix " $A$ " which is called the binary
Table 9 D and E matrices created for consistency ratio control

comparison matrix and the "W" weight matrix were multiplied and the " $D$ " matrix was obtained. 
Using the Eq. (3), the " $D$ " column vector elements were divided into "W" weight matrix elements and the " $E$ " matrix was created (Table 9).

Because there are eleven factors in the study, the value of $\lambda$ was calculated using the Eq. (4) (by taking $n=11$ ). By dividing the sum of each element of the matrix " $E$ " by $n=11$, the value of $\lambda$ was found to be 11.82. With Eq. 5 , consistency indicator " $\mathrm{Cl}$ " value was calculated as 0.082 .

According to the random indicator (RI) table, in an eleven-factor comparison, the RI value is seen as 1.51.

Accordingly, it is seen that the consistency rate (CR) value obtained by dividing the " $C$ "I value by 1.51 is 0.05 . This value is well less than the critical limit of 0.10 , which indicates that the model installed is consistent.

The "kriging method" was used to obtain the solar radiation distribution map in the study area. The reason for this is that there is no solar radiation data for all regions and areas in Nigde.

Kriging is an interpolation method that estimates the optimum values of the data at other points by using the data obtained from the closest known points.

Kriging interpolation method is a technique in which unbiased estimation of positional changes at sampled points using semi-variogram structural properties is optimally made [45].

It is possible to see examples of the kriging method in many studies (Yang [46], Nam and Hur [47]).

\section{Results}

\subsection{Study area}

Nigde is located in Cappadocia of the south-east of Turkey's Central Anatolia region. Nigde is neighbouring Aksaray, Nevsehir, Kayseri and Konya Provinces, is separated from Mersin Province with Bolkar Mountains in the south, and is separated from Adana Province with the natural borders formed by Aladaglar from the south-east and east (Fig. 1).

The high solar energy potential of the Nigde allows the build of the solar plants. Nigde had 10 solar power plants as of 2019.

The lowest power of the solar plants is $1.00 \mathrm{MW}$, and the highest power is $45.00 \mathrm{MW}$. For the 2020 year, 2 solar power plants have been just built [19].

All existing solar power plants are located in Bor and central districts of the Nigde. The location and limits of the study area are shown in Fig. 1.
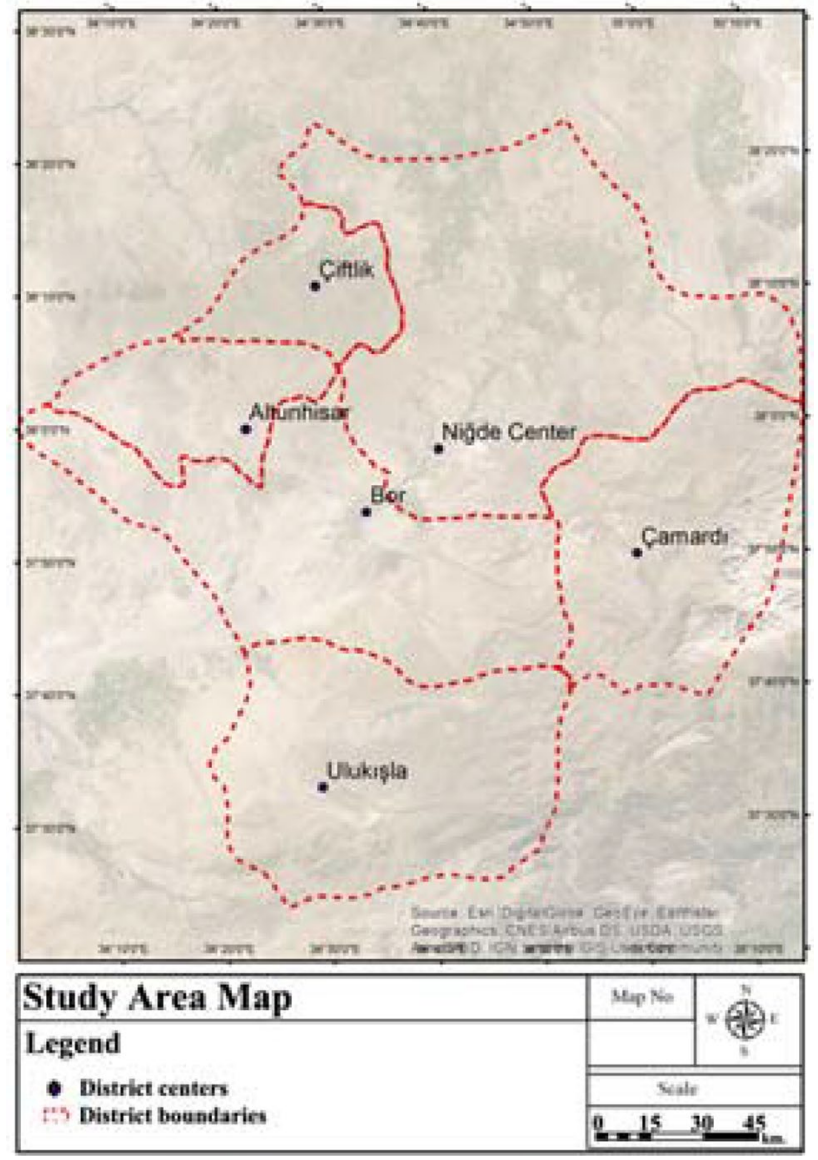

Fig. 1 Study area boundaries

\subsection{Analysis}

\subsubsection{Slope analysis}

Different studies (Garni and Wasthi [41], Jun et al. [9]) suggest different slope values for the site selection in areas where solar energy will be built. Hang et al. [48] stated that the most suitable slope value is between 1 and $3 \%$.

For the site selection, areas that have over $3 \%$ slope are not suitable.

However, in cases where there are no suitable areas with these slope values, However, in cases where there are no suitable areas with these slope values, Miller and Lumby [49] stated that areas that have on $5 \%$ slope can be selected. Various studies (Gasparovic and Gasparovic 2019 [50]) state that $0 \%$ slope areas are not suitable for the build of solar power plants.

In this study, the areas with a score of 3, 4 and 5 are suitable for the build of solar power plants in terms of slope (Fig. 2). 


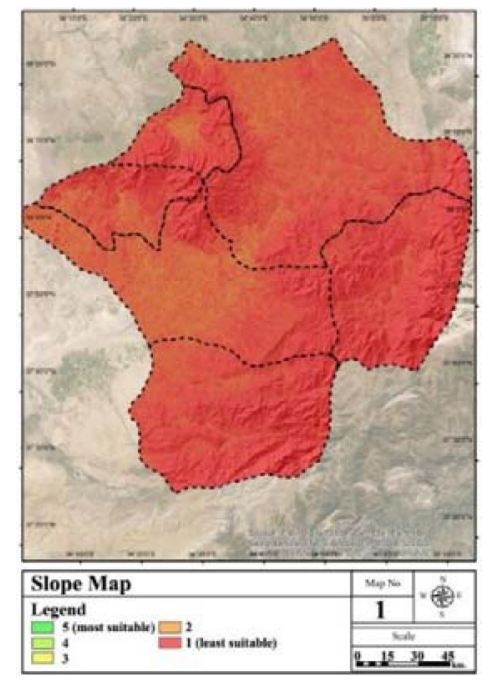

Fig. 2 Slope point map

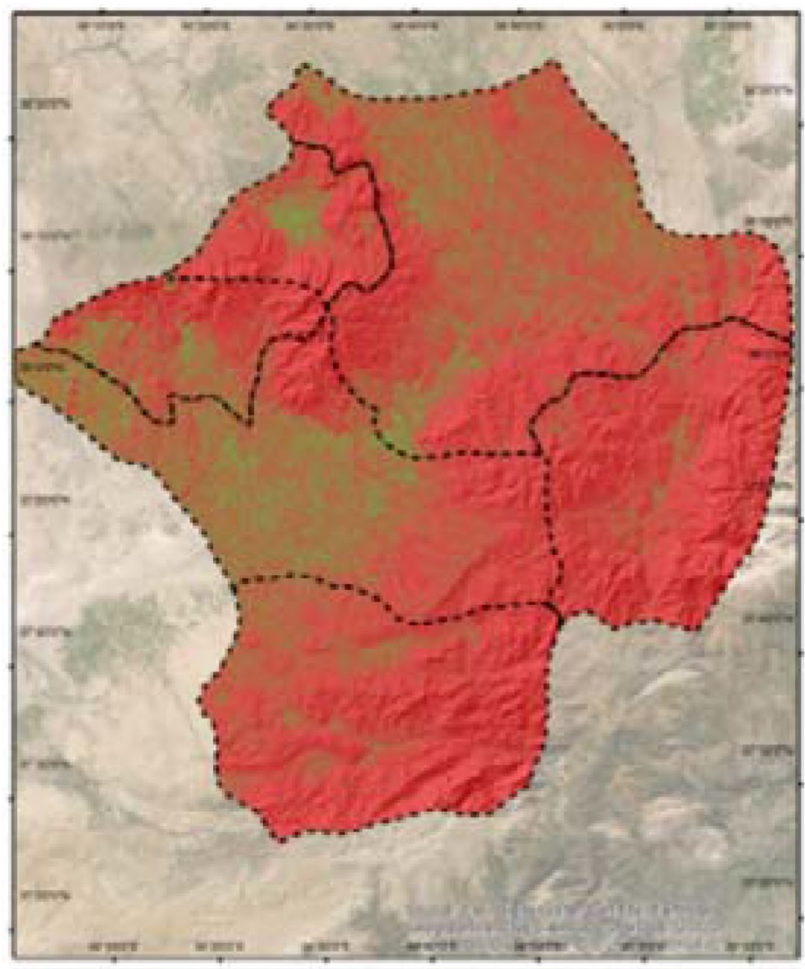

\begin{tabular}{|c|c|c|}
\hline Slope Map & $\tan \mathrm{s}$ & \\
\hline \multirow{3}{*}{ 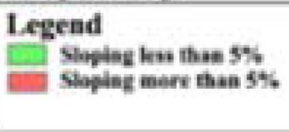 } & 2 & 4 \\
\hline & \multicolumn{2}{|c|}{$8+$} \\
\hline & 2.15 & 4 \\
\hline
\end{tabular}

Fig. 3 Slope map

Slope values were divided into two classes as less than $5 \%$ slope (suitable areas) and more than $5 \%$ slope (unsuitable areas) (Fig. 3).

\subsubsection{Aspect analysis}

Solar power plants should be built in areas that have not shade.

While east, west and south should be preferred, other aspects should not be preferred.

According to Miller and Lumby [49], flat and south aspect should be preferred for the site selection of power plants. Areas with a south aspect provide high sunshine according to different seasonal conditions. Therefore, south aspect is preferred for the solar plants. Aspect maps are created using DEM (digital elevation model). Northern areas were removed from the areas for aspect analysis, and suitable areas are determined as suitable and not suitable and shown on the map (Figs. 4 and 5).

\subsubsection{Traffic network analysis}

According to the environmental impact assessment of the relevant ministry [51], the inappropriateness of the areas within $100 \mathrm{~m}$ of safety lane should be considered. Since the proximity to the traffic networks provide (suitable)

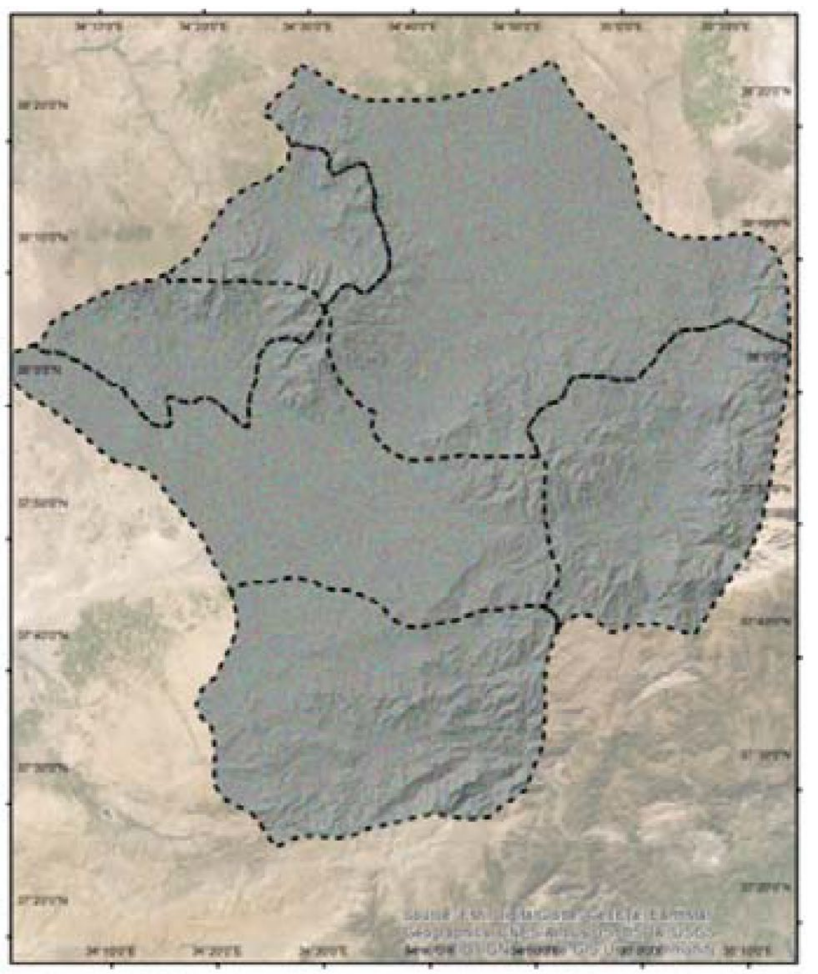

\begin{tabular}{|c|c|c|c|c|}
\hline \multicolumn{3}{|c|}{ Aspect Map } & Mep $\mathrm{Nin}$ & \\
\hline \multirow{3}{*}{\begin{tabular}{|l|} 
Legend \\
Flat \\
Narth \\
Northeast \\
\end{tabular}} & \multirow{3}{*}{$\begin{array}{l}\text { Fast } \\
\text { Southeast } \\
\text { South }\end{array}$} & \multirow{3}{*}{$\begin{array}{l}\text { Southwest } \\
\text { West } \\
\text { Northwest }\end{array}$} & 3 & 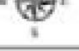 \\
\hline & & & \multicolumn{2}{|c|}{ Scale } \\
\hline & & & 2.15 & 45 \\
\hline
\end{tabular}

Fig. 4 Aspect map 

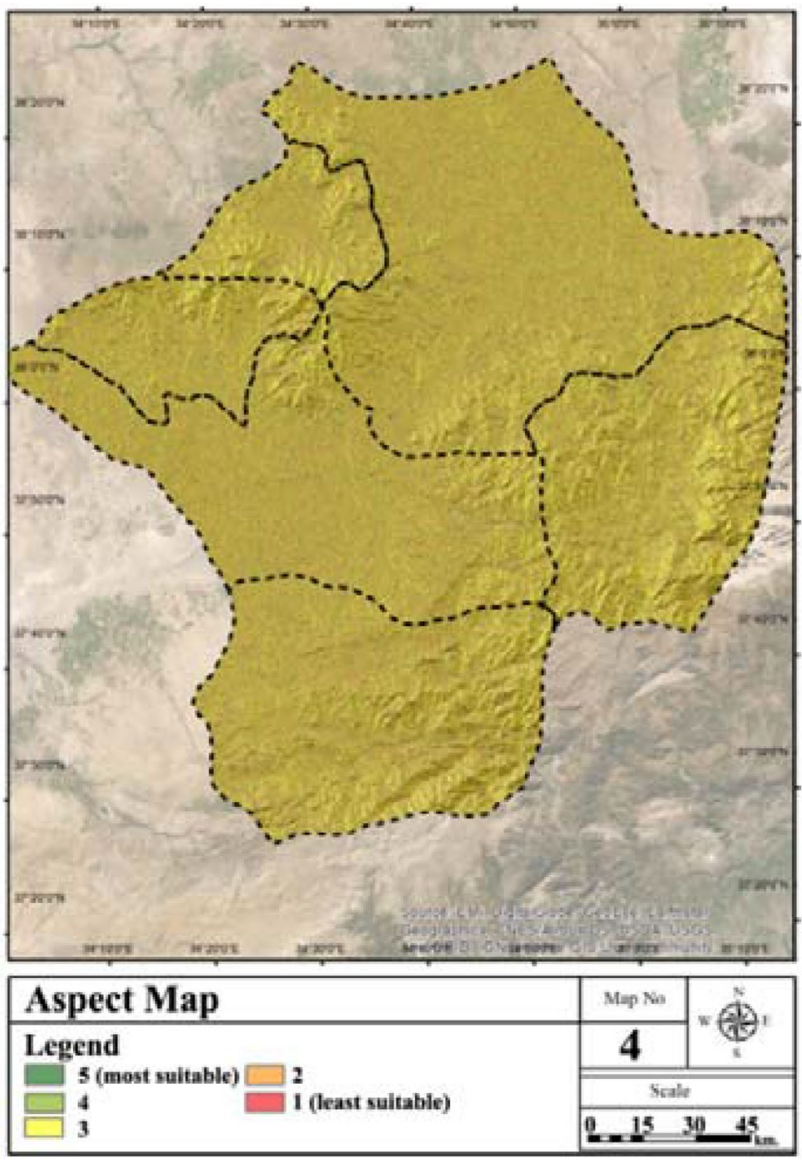

Fig. 5 Aspect point map

advantage, the nearest areas were determined as 5 points (the most suitable). Since the distance to the traffic networks increases the cost and build processes, these areas were determined as 1 points (the least suitable). The map that was created for the traffic network is shown in Fig. 6.

\subsubsection{Power line analysis}

The proximity of the solar power plants to the energy transmission line provides an advantage in terms of efficiency.

The solar power plants to be built in remote areas to power lines increase energy loss and decrease efficiency.

In order to the transfer cost of the energy to be suitable, the nearest areas were determined as 5 points, and remote areas were determined as 1 point. The map that was created for the power lines is shown in Fig. 7.

\subsubsection{Transformer analysis}

The proximity of the solar power plants to be built to the transformer provides an advantage in terms of efficiency.

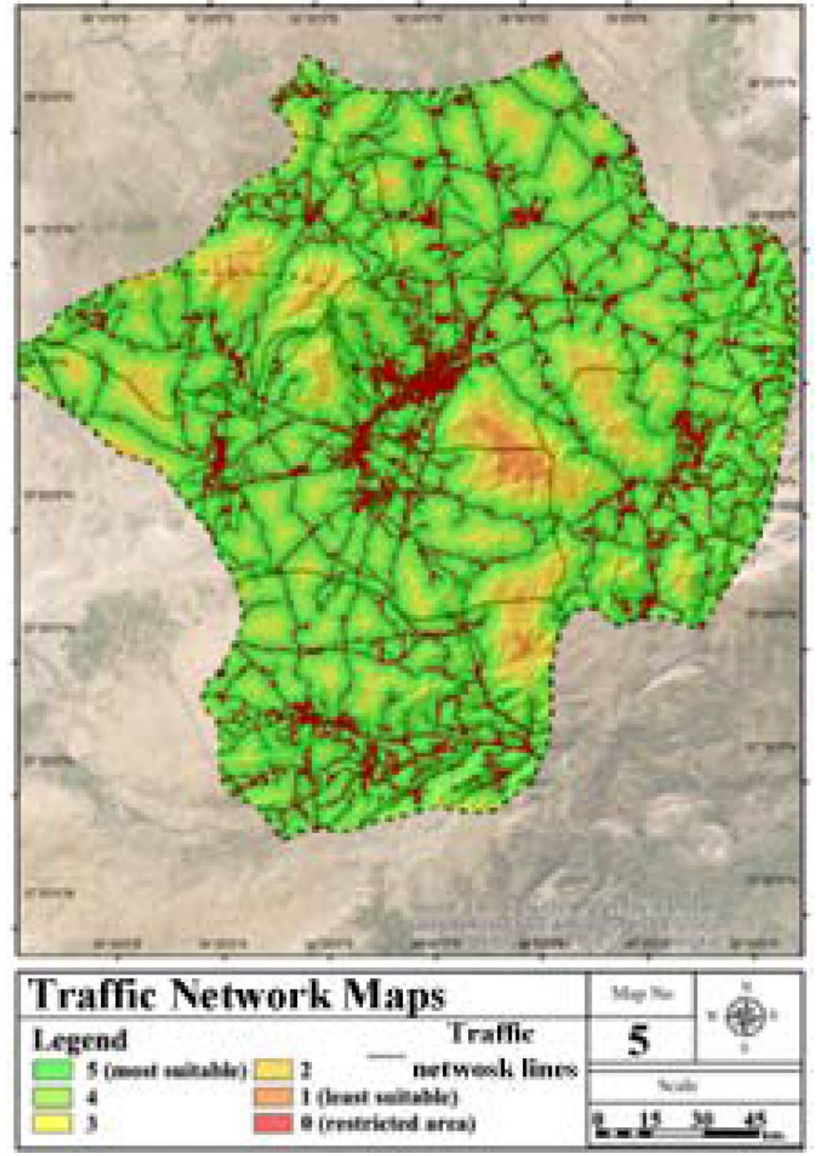

Fig. 6 Traffic network map

Power plants to be built in areas remote to the transformer cause energy loss and decrease efficiency. In the study, the nearest areas were determined as 5 points, and remote areas were determined. The map that was created for the transformers is shown in Fig. 8.

\subsubsection{Solar energy potential analysis}

Information about the sunshine duration and solar radiation was obtained from the stations of the General Directorate of Meteorology [36].

These stations are not available in the entire study area. Therefore, the kriging method was used in order to map the sunshine duration and solar radiation of the entire study area.

The optimum value for solar energy potential is determined to be 2,500 h/year. All districts of the Nigde Province have a sunshine duration above this value. The map that was created for the solar energy potential is shown in Fig. 9. 


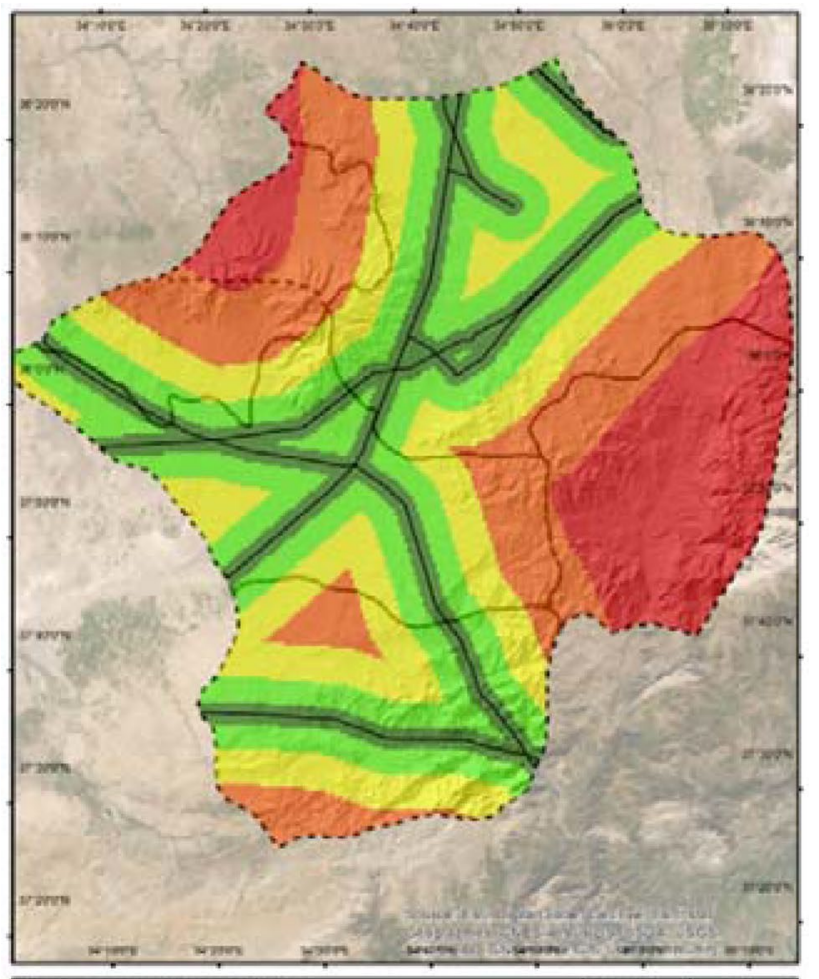

\begin{tabular}{|c|c|c|}
\hline Power Lines Map & $\mathrm{M}=\mathrm{Na}$ & \\
\hline \multirow{3}{*}{ 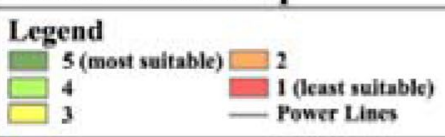 } & 6 & \\
\hline & \multicolumn{2}{|c|}{ Stalle } \\
\hline & 2.15 & 45. \\
\hline
\end{tabular}

Fig. 7 Power line map

\subsubsection{Water source analysis}

If solar plants build near to the rivers, their efficiency decreases due to fog, evaporation, humidity and river flood risk.

It has been determined that the solar plants will be built remote from the water sources.

Areas that are remote from the waters sources were evaluated as most suitable (5 points) and nearest areas were evaluated as least suitable (1 point).

The map that was created for the water source is shown in Fig. 10.

\subsubsection{Fault line analysis}

Fault lines are criteria that should be taken into account for the solar power plant site selection since the study area is located in a tectonically active area.

Areas that are remote from the fault lines are more suitable for the build of solar plants.
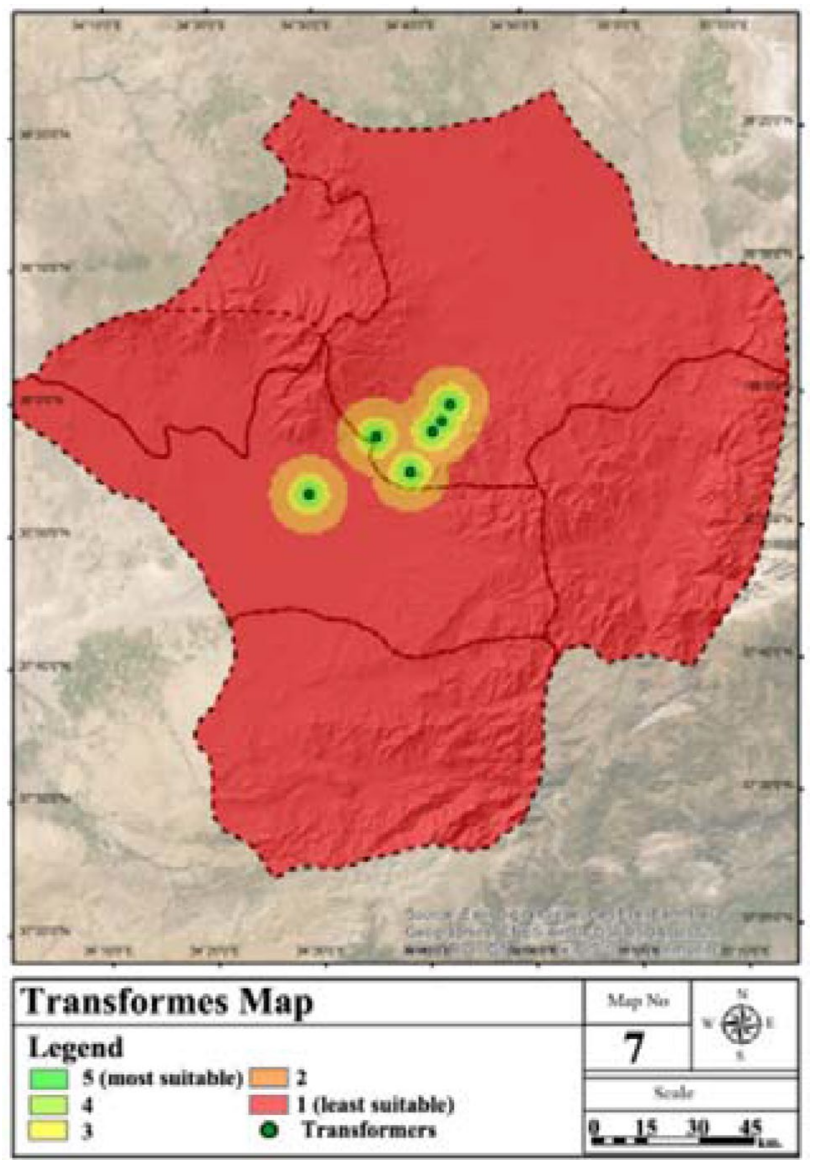

Fig. 8 Transformer analysis map

As it gets closer to the fault lines, suitability decreases. A classification map of the distance to the fault line was created (Fig. 11).

\subsubsection{Residential analysis}

According to Obit [52], solar panel plants should be located in least $5 \mathrm{~km}$ and at most $10 \mathrm{~km}$ from the residential areas. According to the environmental impact assessment of the relevant ministry, it is not suitable for built the solar power plants within $500 \mathrm{~m}$ in the residential areas. The areas up to 5 points (most suitable), 4 points, 3 points and 2 points were determined to be suitable for building a solar power plant in terms of residential areas. The determined distances are visualized with settlement areas conformity map (Fig. 12).

\subsubsection{Mine areas analysis}

Solar power plants should be built in remote areas from the mining areas. The purpose of building the panels 

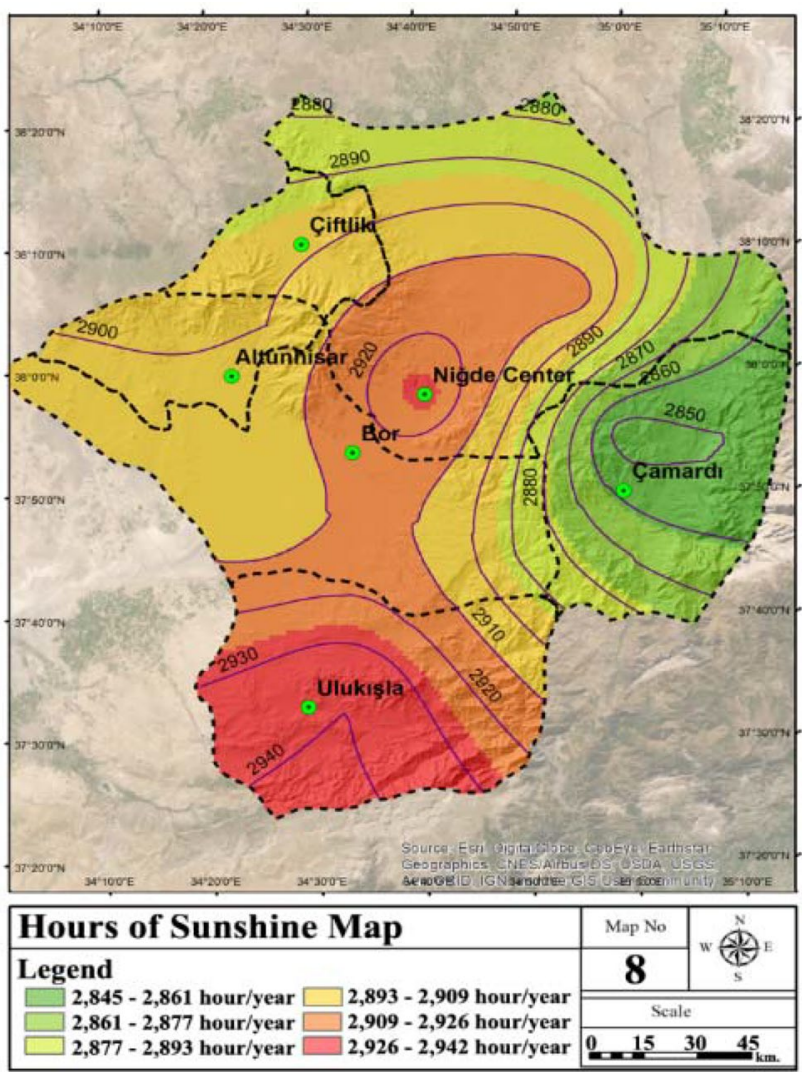

Fig. 9 Sunshine duration map

remote to mining areas is to prevent solar plants from being affected by dust and pollution that may occur by drilling, digging, throwing and filling of mines and quarries. The areas (suitable) distance from the mining areas on the map are shown (Fig. 13).

\subsubsection{Solar radiation analysis}

According to the data obtained from the General Directorate of Renewable Energy (REGD), the lowest radiation level from the sun is between 1500 and $1550 \mathrm{kWh} / \mathrm{m}^{2}$ in Ulukisla district, and the highest solar radiation from the sun is between 1750 and $1800 \mathrm{kwh} / \mathrm{m}^{2}$ in Camardi district in Nigde. Average annual solar radiation is 1650 $\mathrm{kWh} / \mathrm{m}^{2}$ in Nigde [53]. The solar potential of Nigde is given in Fig. 14 [54].

The areas where the solar power plant can be built in the Nigde Province, Euclidean distance for each layer, sunshine duration, solar radiation, slope, aspect, proximity to the power line, proximity to transformers, distance to water resource areas, distance to fault line, proximity to residential areas, distance to mining areas, and proximity to road were obtained and shown in the maps. As a result of combining the layers classified in the intervals
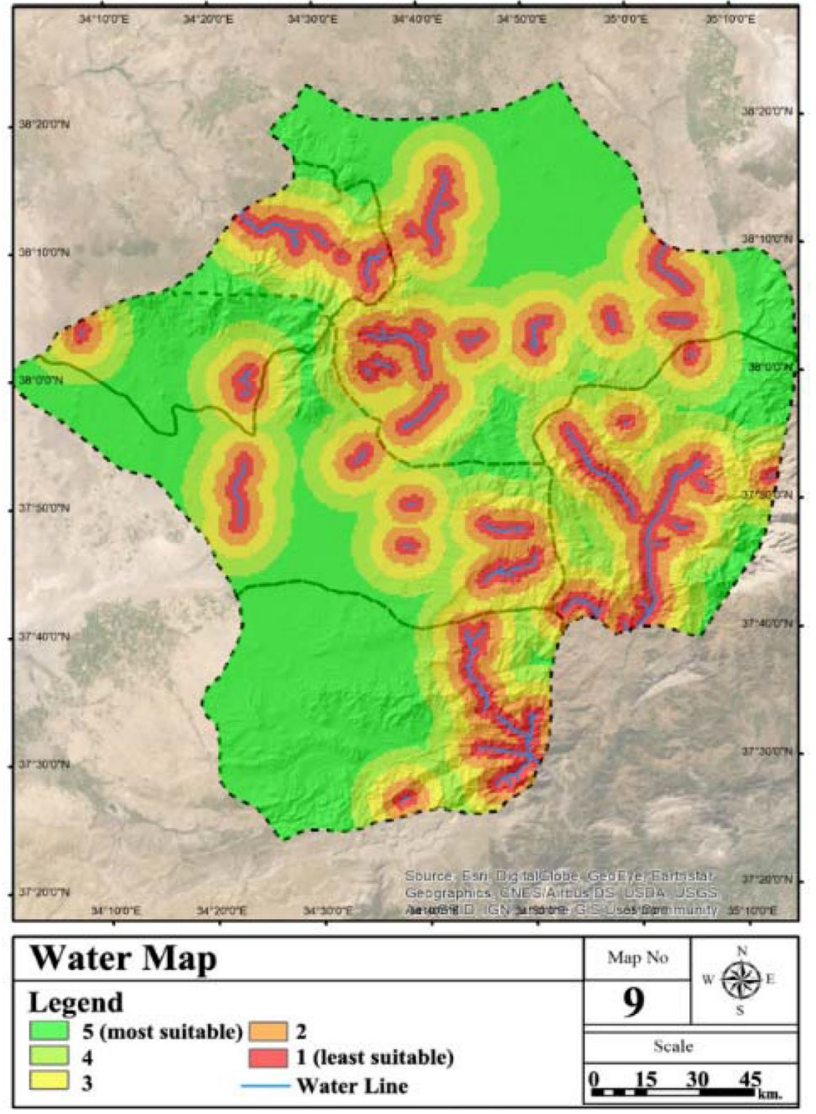

Fig. 10 Water map

determined by using Eq. (7), a single raster layer was created for the suitable areas. Suitable areas where a solar power plant could be built were determined in the study area.

However, residential areas, water surfaces and agricultural areas were removed from the map that was obtained before. Since the area sizes and populations of the residential areas will vary, it has been removed from the map.

Agricultural areas were removed from the map due to the ecological and economic contributions that they provided. Land-use/land-cover map was created for these reason. Land-cover/land-use map is shown Fig. 15. The map that shows the most suitable areas for solar panels in Nigde is given in Fig. 16.

\subsection{Evaluation of the study area in terms of the build of solar panels}

Suitable areas where a solar power plant could be built were determined in the study area. As a result of the analysis, the most suitable areas to build a solar power plant are the north-west and eastern part of Nigde. 


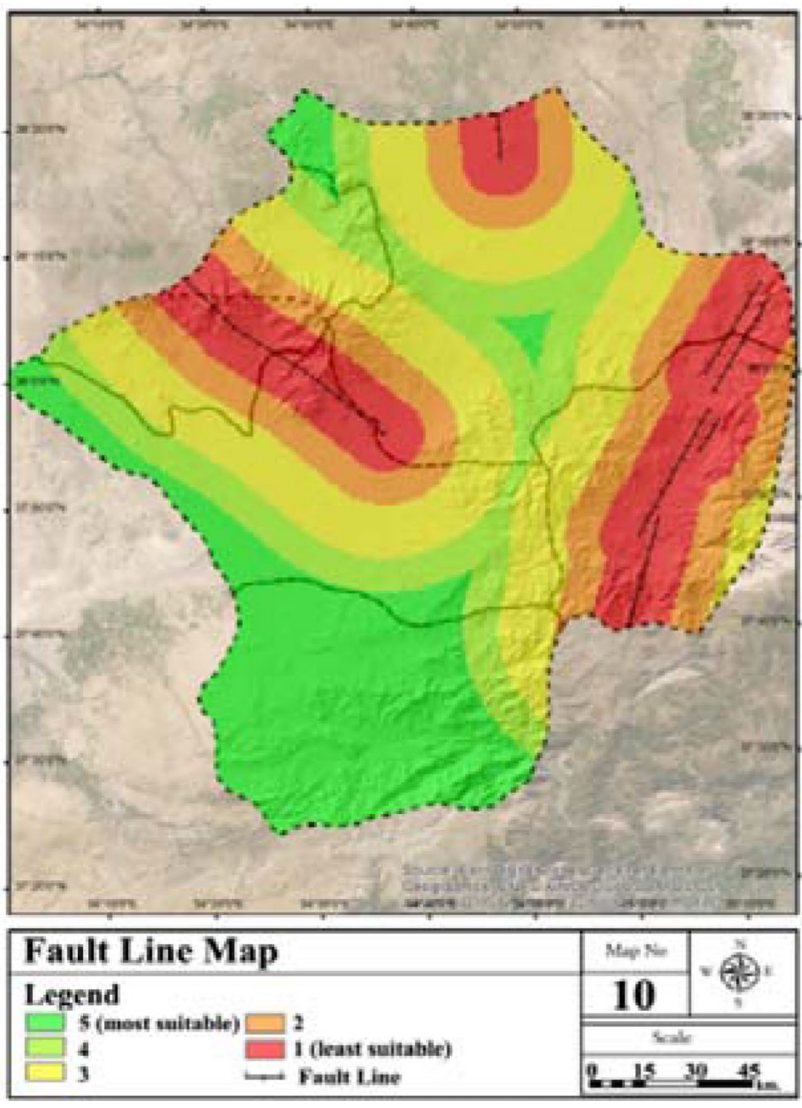

Fig. 11 Fault line map

However, it has been determined that the middle parts of the study area are not suitable for the build of solar plants.

When the study area was examined for the solar panel build, the highest score was 4 point. According to the results, 5 points and 1 point could not be obtained from the study area. When the districts with the highest or lowest eligibility in selecting the location for solar plants are examined, there is no suitable place for solar plant in Camardi district.

After Camardi district, the area with the least suitable place for solar plants is Ciftlik district. The district with the highest potential solar plant areas is Ulukisla. With the field study conducted in Nigde, 8 of the 10 solar power plants were determined to be in suitable areas determined on the map.

Thus, it was determined that correct results were obtained from the final map. However, all of the existing solar plants are located in Bor and central districts of the Nigde. According to the results of the analysis, it is suitable to build solar plants in Bor district. However, the central district has very little suitable place for the build of solar plants. For this reason, solar plants to be built to Nigde later on should be constructed in Ulukisla district.
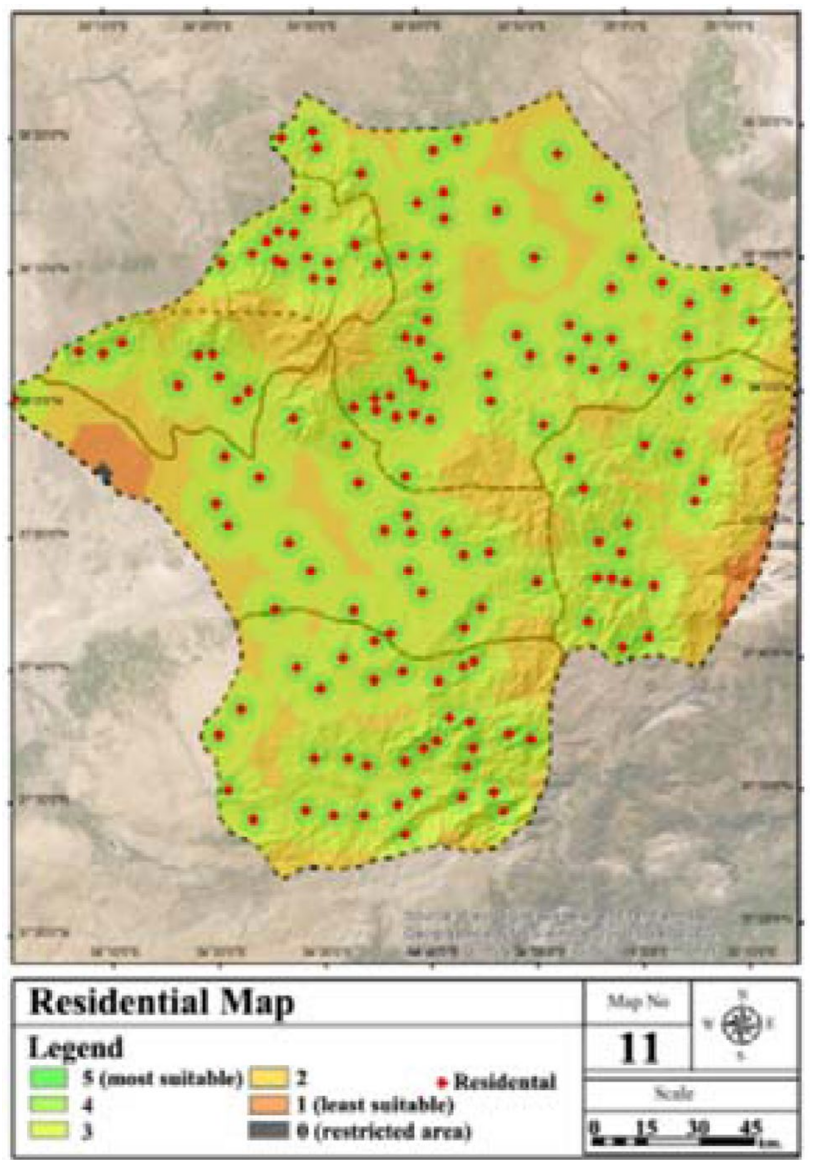

Fig. 12 Residential map

We can say that central district can be selected due to factors such as accessibility, cost and sun. However, the central district should not be preferred for the solar plants to be built from now on, in order to obtain higher efficiency from the plants and no less damage to the natural environment.

There are some problems regarding the site selection of solar panels in Nigde Province. The topography of Nigde Province has a wavy structure. Therefore, it is very difficult to find a flat area except for the central and Bor districts. This causes the cost to increase. In other districts, the topographical structure of the areas other than residential areas is very wavy.

Therefore, most of the existing panels are located in central and Bor districts for various reasons such as cost and labour. However, as a result of the analyses, it was determined that these two districts are less suitable than other districts.

In particular, Ulukisla district has the highest values in terms of solar potential in Nigde. Failure to make panels in these areas only due to topography causes losses in terms of energy efficiency. Suitable areas should be created for 


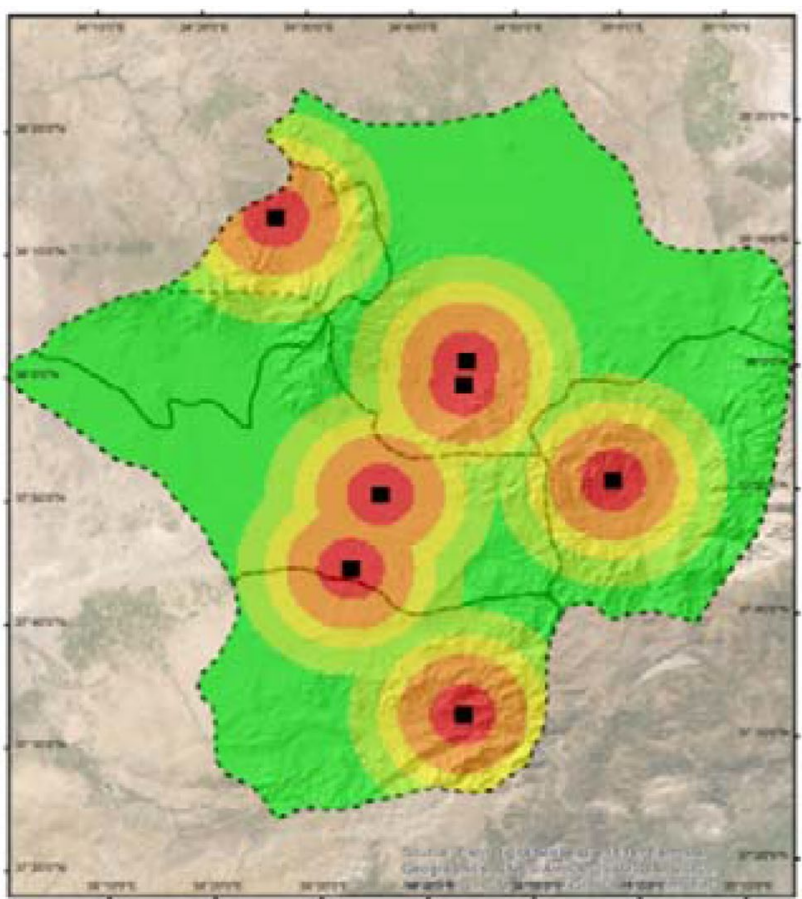

\begin{tabular}{|c|c|c|}
\hline Mining Area Map & Map $\mathrm{Nin}_{\text {in }}$ & \\
\hline \multirow{3}{*}{$\begin{array}{l}\text { Legend } \\
\begin{array}{|l}5 \text { (mant sultable) } \square \\
4 \\
3\end{array} \\
3\end{array}$} & 12 & \\
\hline & \multicolumn{2}{|c|}{ Sonta } \\
\hline & 2.15 & 45 \\
\hline
\end{tabular}

Fig. 13 Mining map

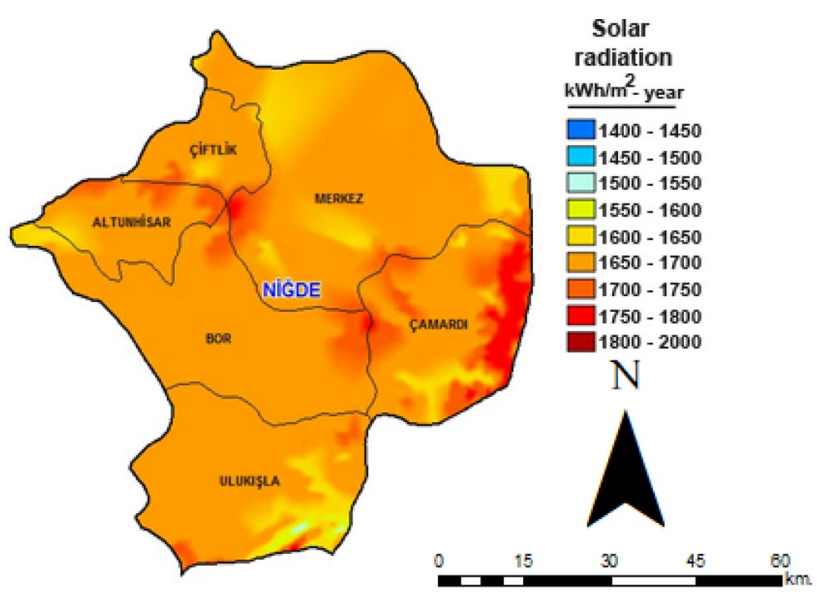

Fig. 14 Solar radiation map of Nigde

the built of the panels with new planning studies and engineering calculations (such as excavation-fill) to be made in these areas. Although these plans are high in terms of initial cost, considering the value of the energy to be obtained, these costs will be worthless. Although

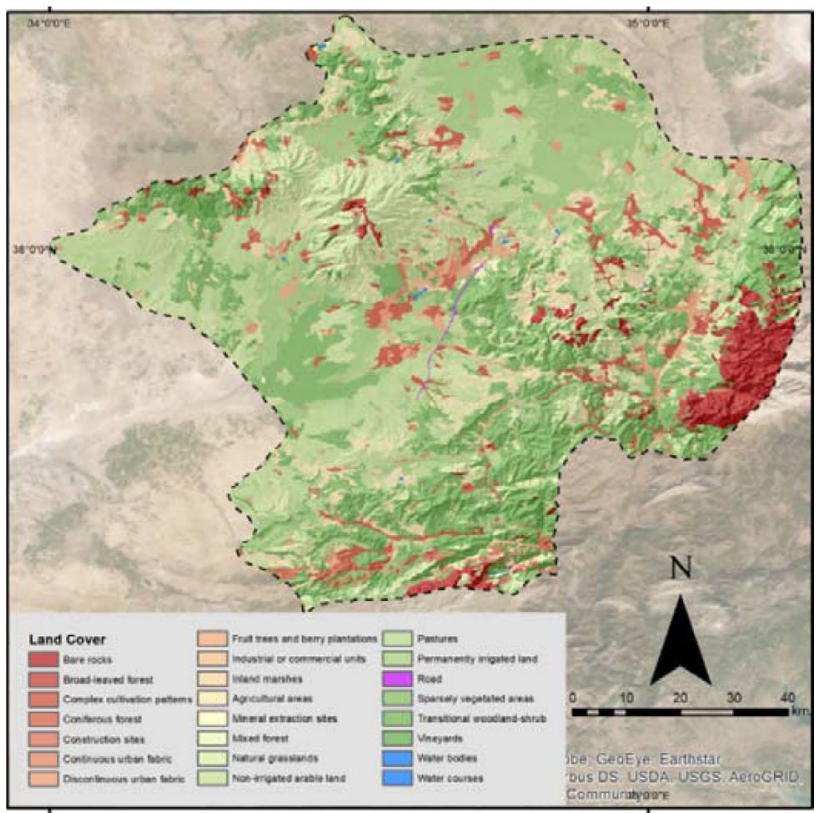

Fig. 15 Land cover of Nigde

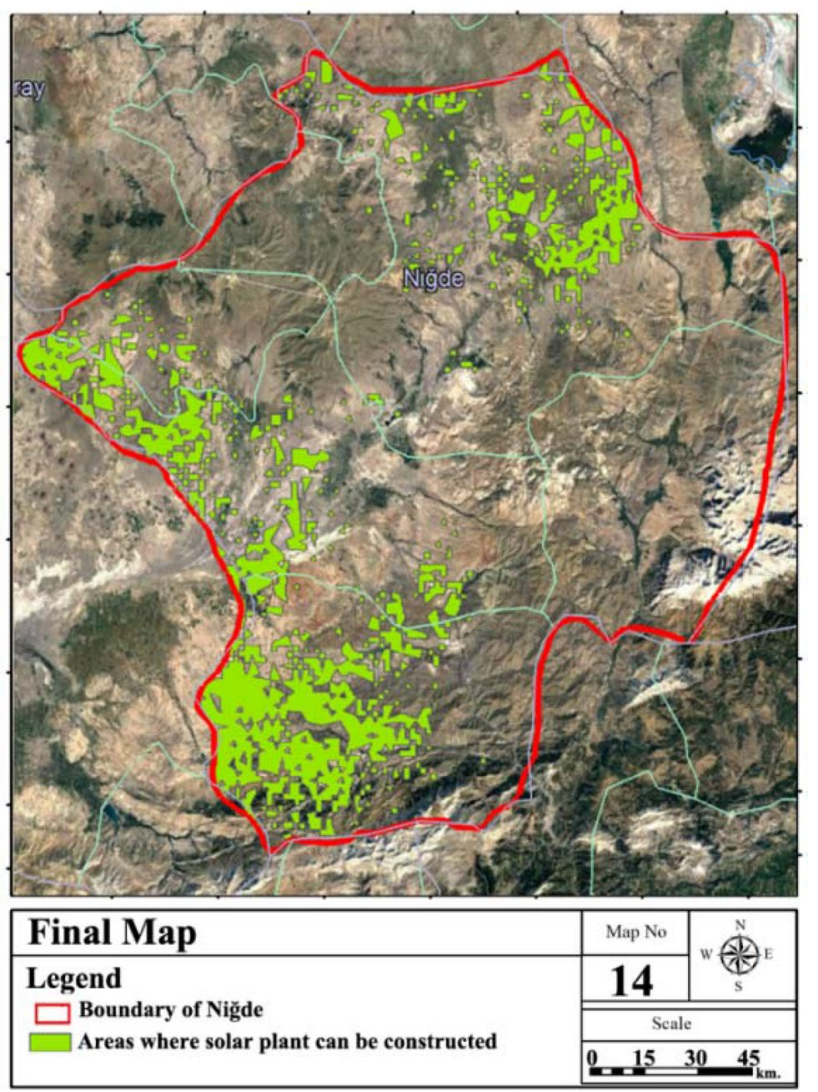

Fig. 16 Areas where solar panels can be built 
this topographic structure of the Nigde causes problems in terms of built, it offers some advantages.

First of all, due to this topographic structure, the sunshine duration and solar radiation rate of Nigde are high. As a result of the analysis, it has been determined that $37.46 \%$ of the Nigde has south, south-east, south-west and flat aspects. Considering that in particular the south views area is a region with a lot of sun, we can say that Nigde Province has a great importance in terms of solar energy potential. The province of Nigde is in a region that has a "valley" appearance as an urban silhouette. Therefore, in particular high areas get a lot of sun. Using solar panels for built in these areas will provide serious gains in terms of energy costs not only for the province of Nigde, but also for its immediate surroundings.

Although the energy cost of Nigde is not as much as Istanbul or Ankara, which are large metropolitan cities in Turkey, urbanization causes increase to energy cost. Therefore, with the increasing number of buildings, traffic and industrial facilities near the city, the energy cost in Nigde is increasing. Despite the increase in energy costs and the high potential of Nigde in terms of solar energy, the number of solar panels in Nigde and the number of incentives and investments for the panels are quite insufficient. There are 10 solar panels in Nigde Province. Ankara which is the capital city of Turkey has solar radiation rate of $1,473 \mathrm{kWh} /$ year, according to which the Nigde potential is quite low (proportion of the province of Nigde solar radiation 1,620 $\mathrm{kWh} /$ year) [19].

Despite this disadvantage, there are a total of 50 solar panels in Ankara Province. Although they are similar in terms of topography and climate, this difference between the number of panels causes losses in terms of energy efficiency.

We can say that this difference is due to reasons such as the fact that Nigde has less industry compared to other provinces and its population is less than other regions. However, these factors are not used for the site selection of solar panels in any study, including this study.

For this reason, the solar potential of the Nigde should be considered, not the population density or its industrial, and planning should be made accordingly.

\section{Conclusion}

In today's world, energy consumption is increasing day by day. Societies have to increase their competitiveness, grow their economies and improve their quality of life for their level of technological development. Production of clean energy is of great importance in ensuring technological development and sustainability. Solar energy, which is among the renewable energy sources, is stated to be environmentally friendly as their source is both abundant and a continuous and renewable energy source.

AHP (analytical hierarchy process) method was used to evaluate the factors in the study. The method was found suitable in terms of taking into account more than one factor, revealed the relationships between the factors quantitatively and calculated the consistency rate using various analyses. However, the get difficult of mathematical process with the increase in factors was determined as the deficient features of the method.

This result was compared with the previous studies. Kum et al. [7] stated that the AHP method suitable for solar panels site selection in their study. Garni and Awasthi [41] used the AHP method in their study on the site selection of solar panels in Saudi Arabia and concluded that the method is suitable for such studies. In this respect, this study is similar to previous studies on the subject. However, other studies did not state any results regarding the number of factors. This study differs from other studies in this respect.

In this study, 11 factors were used to determine the most suitable areas for solar panels. When the studies on the subject are examined, the number of factors is sufficient. Solangi et al. [55] used 6 factors in their study such as orography, environment, climate, economy, topography and social criteria. These factors were also used in this study.

Wiguna et al. [56] used 6 factors in their study such as distance to residential area, slope, aspect, distance to road, distance to energy sources and solar radiation. These factors were used within the scope of the study. Therefore, the factors used in the study are quantitatively and qualitatively suitable. Although very few, we can say that rainfall data are also used in some studies on the subject. Rainfall data were not used in this study.

This is one of the shortcomings of the study, and this is entirely related to the region that was studied. Nigde Province is located in an area that as not much rainfall. These data were not included in the factors, as the use of precipitation data was not considered to affect the result. The biggest problem in terms of climate for the Nigde is "frost" in the winter months. This is a problem in the whole city. Therefore, it was not included in the study. The most important factors that affect the site selection of solar panels were the sunshine duration and solar radiation with a rate of $23 \%$. Sunshine duration was the factor with the highest rate in the previous studies. Tunç et al. [57] in their study in Istanbul, Turkey, found the sunshine duration as the most important factor.

Also, similar results have been found in many studies. However, it should not be forgotten that these results will change with the characteristics of the region and the ratio of the number of factors. This ratio may decrease or 
increase depending on the number of factors that will be used. It should not be forgotten that these values belong to this study, since the climatic characteristics and topographic structure of the region will change these results.

The study has scientific innovations as well as deficiencies. In previous studies, land use/land cover was not among the factors. In this study, it was determined that the land use/land cover is an important factor for the build of solar panels, and the land use/land cover can change the results. When other factors such as the distance to transformer centres and roads are taken into account besides the land use/land cover, the results will be changed. The determination of the analyses and the suitability map made in the study with the existing status of the land show the accuracy of the results. The determined areas will contribute to the economy of the country and meet the energy needs of this region.

Solar energy, which has become a new research area and at the same time an energy source for the countries, will help to make site selection studies based on multicriteria. Because, since in recent years, Turkey's policy towards renewable energy consequently arises questions that need to be established where will be the solar PV power plants, this study will serve as an example to this question for decision-making support system.

In order to benefit from renewable energy at the highest level, it is necessary to use GIS more effectively and to expand the field of work in future studies. In addition, the results of the energy values obtained from the solar panels to be built in the suggested areas should be measured, and the accuracy of the study should be clearly demonstrated. One of the shortcomings of the study is that the results obtained in this study could not be applied on the land.

Studies are made to these issues in Turkey for more metropolitan cities. The fact that this study was carried out in underdeveloped cities such as Nigde will be an example for future studies.

When Nigde Solar Energy power plants are evaluated in terms of location selection efficiency criteria, it is seen that the location selection decision is suitable.

When the suitable locations are evaluated in terms of environmental impact, it has been determined that the agricultural areas will not be affected by the power plants since the land-use capability 1, 2, 3 and 4 class.

The situation that is expected to be the most ecologically affected by solar power plants is that the birds are affected by the reflected light from the plants. Nigde is located on the seasonal migration route of the birds.

However, it is expected that this effect will be at the minimum level since the plants are located in remote areas to the river and lake areas.
As of 2019, Turkey also reached 1,362.60 MW of built solar power. $108 \mathrm{MW}$ energy is produced from solar energy plants located in Nigde Province [19]. It has been determined that $18 \%$ of annual consumption in Nigde Province originates from solar plants. "Active use of the Renewable Energy systems transformation project" statement is included in the strategic plan report of Nigde Municipality covering 2015-2019 [58]. This study will be the reference for the solar plants to be made from now on.

Landscape design elements should be considered during the positioning of the solar plants. The areas that will allow solar plants to get sun should not be covered with vegetative elements. The south facade, which will allow the plants to take the sun, must be open. In order to remove the visual pollution that will occur as a result of positioning the plants, the areas outside the south facade should be covered with vegetative elements.

It may be suggested that the areas next to the electrical transformers should be left blank for the future solar plants, to reduce the build cost of the transmission cables to the substations, which will allow this energy to be stored and distributed after electricity generation.

As a result of the meeting with experts, 20 acres of land should be considered for each $1 \mathrm{MW}$ solar plant, and the area usage planning should be done according to this criterion.

Comparing environmental impact assessment of solar power plants to other power plants, it has been determined to have less impact than other plants. The visual effect of the power plants is high and the noise effect is almost non-existent.

These evaluations show that solar power plants do not produce clean energy completely, they have various environmental effects, but as a result of comparisons, solar power plants have less effect than thermal power plants. It is an acceptable fact that the energy produced, regardless of its source, has various effects on the environment.

The discourses, policies and practices regarding the fact that solar energy generation systems are a completely clean energy source do not match. In this respect, it is recommended that solar energy is preferred in terms of energy production, considering it to be a cleaner energy production source compared to fossil fuel power plants, less destruction to the environment and being renewable. Nevertheless, it is very important to evaluate the environmental dimensions of solar power plants and to make applications that will minimize their environmental impact and to make location selection decisions [59].

Author contributions O.S. took part in the creation, analysis and interpretation of the maps and wrote the article. 


\section{Compliance with ethical standards}

Conflict of interest No potential conflict of interest was reported by the authors.

Open Access This article is licensed under a Creative Commons Attribution 4.0 International License, which permits use, sharing, adaptation, distribution and reproduction in any medium or format, as long as you give appropriate credit to the original author(s) and the source, provide a link to the Creative Commons licence, and indicate if changes were made. The images or other third party material in this article are included in the article's Creative Commons licence, unless indicated otherwise in a credit line to the material. If material is not included in the article's Creative Commons licence and your intended use is not permitted by statutory regulation or exceeds the permitted use, you will need to obtain permission directly from the copyright holder. To view a copy of this licence, visit http://creativecommons .org/licenses/by/4.0/.

\section{References}

1. Asakereh A, Soleymani M, Sheikhdavoodi MJ (2017) A GISbased Fuzzy-AHP method for the evaluation of solar farms locations: case study in Khuzestan province. Iran Sol Energy 155:342-353

2. Huang W, Chen W, Anandarajah G (2017) The role of technology diffusion in a decarbonizing world to limit global warming to well below 2 C: An assessment with application of Global TIMES model. Appl Energy 208:291-301

3. Fthenakis V, Alsema E (2006) Photovoltaics energy payback times, greenhouse gas emissions and external costs: 2004-early 2005 status. Prog Photovolt Res Appl 14(3):275-280

4. Finance BNE (2018) Global Trends in Renewable Energy Investment Report 2018, FS-UNEP Collaborating Centre for Climate \& Sustainable Energy Finance, Germany, p 86

5. Renewable Energy Policy (2018). REN21 Renewables 2018 global status report. Retrieved from https://www.ren21.net/gsr-2019/ chapters/chapter_01/chapter_01/

6. Kumbur H, Özer Z, Özsoy HD, Avcı ED (2015) Comparison of the potential environmental impact of conventional and renewable energy sources in Turkey. Yeksem 2015, III. Renew Energy Res Symp Exhib 1:19-21

7. Gülşen K, Sönmez ME, Karabaş M (2019) Determination of solar energy potential in Gaziantep Province using analytical hierarchy process method (AHP). Geogr Rev 39:61-72

8. Raugei M, Fullana-i-Palmer P, Fthenakis V (2012) The energy return on energy investment (EROI) of photovoltaics: Methodology and comparisons with fossil fuel life cycles. Energy Policy 45:576-582

9. Jung J, Han S, Kim B (2019) Digital numerical map-oriented estimation of solar energy potential for site selection of photovoltaic solar panels on national highway slopes. Appl Energy 242:57-68

10. Lu H, Zhao W (2018) Effects of particle sizes and tilt angles on dust deposition characteristics of a ground-mounted solar photovoltaic system. Appl Energy 220:514-526

11. Philibert C, Frankl P, Tam C, Abdelilah Y, Bahar H, Marchais Q, Wiesner H (2014) Technology roadmap: solar photovoltaic energy. International Energy Agency, Paris, France, $60 \mathrm{p}$

12. Soydan O (2018) Evaluation of the landscape design of Niğde Ömer Halisdemir University campus in terms of lighting quality and energy efficiency. Akdeniz University, Landscape Architecture Department Doctoral Thesis, Antalya, Turkey, $253 \mathrm{p}$.

13. Bicer Y, Dincer I (2017) Life cycle evaluation of hydrogen and other potential fuels for aircrafts. Int J Hydrogen Energy 42(16):10722-10738

14. Jaffery SHI, Ali L, Khan M, Qureshi HM, Khan M, Ahsan Z, Khan HA (2015) Development and testing of a solar cell test chamber for performance evaluation of solar cells. In: 2015 50th International universities power engineering conference (UPEC). IEEE, pp 1-4

15. Abas N, Kalair A, Khan N (2015) Review of fossil fuels and future energy technologies. Futures 69:31-49

16. Kabir E, Kumar P, Kumar S, Adelodun AA, Kim KH (2018) Solar energy: potential and future prospects. Renew Sustain Energy Rev 82:894-900

17. Campana PE, Wästhage L, Nookuea W, Tan Y, Yan J (2019) Optimization and assessment of floating and floating-tracking PV systems integrated in on-and off-grid hybrid energy systems. Sol Energy 177:782-795

18. Cebeci S (2017) Evaluation of the potential electricity production from solar energy in Turkey. General Directorate of Economic Sectors and Coordination, Master Thesis, p, 20.

19. Ministry of Energy and Natural Resources of Turkey. (2019). Energy Report of Turkey. https://www.enerji.gov.tr/

20. Bağcı E (2019) Renewable energy potential in Turkey, production, consumption and current account balance relationship. $\mathrm{R}$ \& S-Res Stud Anatolia J 2(4):101-117

21. Kaynar NK (2020) Potential of solar energy from renewable energy sources in Amasya Province. Bilge Int J Sci Technol Res 4(2):48-54

22. Klepacka AM, Florkowski WJ, Meng T (2018) Clean, accessible, and cost-saving: Reasons for rural household investment in solar panels in Poland. Resour Conserv Recycl 139:338-350

23. Bayrakçı HC, GezerT (2019) Cost analysis of a solar power plant: the case of Aydın Province. J Tech Sci 9(2):46-54

24. Baka M, Manganiello P, Soudris D, Catthoor F (2019) A cost-benefit analysis for reconfigurable PV modules under shading. Sol Energy 178:69-78

25. Strielkowski W, Volkova E, Pushkareva L, Streimikiene D (2019) Innovative policies for energy efficiency and the use of renewables in households. Energies 12(7):1392

26. Da Cunha SRL, de Aguiar JLB (2020) Phase change materials and energy efficiency of buildings: A review of knowledge. J Energy Storage 27:101083

27. Kocaman AS, Ozyoruk E, Taneja S, Modi V (2020) A stochastic framework to evaluate the impact of agricultural load flexibility on the sizing of renewable energy systems. Renew Energy 152:1067-1078

28. Koc A, Turk S, Şahin G (2019) Multi-criteria of wind-solar site selection problem using a GIS-AHP-based approach with an application in Igdir Province/Turkey. Environ Sci Pollut Res 26(31):32298-32310

29. Wang W, Shi Y, Zhang C, Hong S, Shi L, Chang J, Wang P (2019) Simultaneous production of fresh water and electricity via multistage solar photovoltaic membrane distillation. Nature Commun 10(1):1-9

30. Alsabbagh M (2019) Public perception toward residential solar panels in Bahrain. Energy Rep 5:253-261

31. Suri $D$ (2020) Site selection framework for mini-grids in developing countries: an overview. Electric J 33(7):106803

32. Geçen R (2019) Determination of areas of solar energy potential and solar power plant in Hatay Province. Soc Sci 14(6):3031-3054

33. Sarsicı N (2020) Determination of areas where solar power plants can be established in Karabük province by Multi-Criteria 
Decision Analysis, Karabük University, Department of Geography, Master Thesis, 193 p., Karabük Turkey.

34. Oral B, Sağlam S, Mellit A (2020, April) Analysis of a BuildingMounted Wind-Solar Hybrid Power System in Urban Residential Areas: The Case Study of Istanbul. In: International conference on electronic engineering and renewable energy, Springer, Singapore, pp 729-737

35. Keskin A (2019) Nigde Province Solar Power Plant Modelling and Evaluation of Performance Parameters. Gazi University, Institute of Science, Master's Thesis, 128 p., Ankara, Turkey.

36. General Directorate of Meteorology (2019) Chart of Antalya City rainfall intensity over time. Ankara: Republic of Turkey, Ministry of Agriculture and Forestry, General Directorate of Meteorology.

37. Bokaie M, Zarkesh MK, Arasteh PD, Hosseini A (2016) Assessment of urban heat island based on the relationship between land surface temperature and land use/land cover in Tehran. Sustain Cities Soc 23:94-104

38. Yang C, He X, Yan F, Yu L, Bu K, Yang J, Zhang S (2017) Mapping the influence of land use/land cover changes on the urban heat island effect-A case study of Changchun. China Sustain $9(2): 312$

39. Dağdeviren $M$, Tamer E (2001) Analytical hierarchy process and use of 0-1 goal programming methods in supplier selection. Gazi Univ J Eng Archit Fac 16(1):41-52

40. Toksarı M (2007) Determining the target market for the furniture industry in the Aegean region using analytical hierarchy process approach. Manag Econ 14(1):171-180

41. Al Garni HZ, Awasthi A (2017) Solar PV power plant site selection using a GIS-AHP based approach with application in Saudi Arabia. Appl Energy 206:1225-1240

42. Çolak M, Kaya I (2020) Multi-criteria evaluation of energy storage technologies based on hesitant fuzzy information: a case study for Turkey. J Energy Storage 28:101211

43. Saaty TL (1977) A scaling method for priorities in hierarchical structures. J Math Psychol 15(3):234-281

44. Dilekçi S, Marangoz AM, Ateşoglu A (2019) Zonguldak and Eregli forest management directorates of forestry fire risk areas determination. J Geomatik 6(1):44-53

45. Yaprak S, Arslan E (2008) Kriging method and interpolation of geoit heights. J Geod Jeoinformation 98:36-42

46. Yang $D$ (2018) Spatial prediction using kriging ensemble. Sol Energy 171:977-982

47. Nam S, Hur J (2019) A hybrid spatio-temporal forecasting of solar generating resources for grid integration. Energy 177:503-510
48. Hang LAN (2008) Analysis of zone safety degree of slopes and its application based on FLAC3D. J China Univ Min Technol 37(4):570-574

49. Miller A, Lumby B (2012) Utility scale solar power plants: a guide for developers and investors. Guidelines book written for IFC. World Bank Group, New Delhi, India

50. Gašparović I, Gašparović M (2019) Determining optimal solar power plant locations based on remote sensing and GIS methods: A case study from Croatia. Remote Sens 11(12):1481

51. Ministry of Environment and Urban (2016). Environmental assessment report. https://csb.gov.tr/

52. Obut $Z$ (2016) Determination of the area which solar plant will be established in Goksun by GIS method. Kahramanmaraş Sütçü Imam University, Department of Geography Institute Of Social Sciences, Master Thesis, 71 p., Kahramanmaraş, Turkey.

53. Özdemir S, Şahin G (2018) Multi-criteria decision-making in the location selection for a solar PV power plant using AHP. Measurement 129:218-226

54. Sake T (2015) Analysis of wind and solar energy technologies and evaluating the applicability of the province of Nigde. Graduate School of Natural and Applied Sciences / Environmental Engineering Department Master Thesis, $117 \mathrm{p}$.

55. Solangi YA, Shah SAA, Zameer H, Ikram M, Saracoglu BO (2019) Assessing the solar PV power project site selection in Pakistan: Based on AHP-fuzzy VIKOR approach. Environ Sci Pollut Res 26(29):30286-30302

56. Wiguna KA, Sarno R, Ariyani NF (2016) Optimization solar farm site selection using multi-criteria decision-making fuzzy AHP and PROMETHEE: case study in Bali. In: 2016 International conference on information \& communication technology and systems (ICTS). IEEE, pp 237-243.

57. Tunc A, Tuncay G, Alacakanat Z, Sevimli FS (2019) Gis based solar power plants site selection using analytic hierarchy process (Ahp) in Istanbul Turkey. Int Arch Photogramm Remote Sens Spat Inf Sci XLII-2/W13:1353-1360

58. Sak T, Gönen Ç, Kara E (2019) Expansion of solar power plants and potential of reducing greenhouse gas emissions in Niğde Province. Firat Univ J Eng Sci 31(2):327-335

59. Xu Y, Li J, Tan Q, Peters AL, Yang C (2018) Global status of recycling waste solar panels: a review. Waste Manage 75:450-458

Publisher's Note Springer Nature remains neutral with regard to jurisdictional claims in published maps and institutional affiliations. 